\title{
I - Análise dos dados de mortalidade
}

\section{I - Analysis of mortality data}

\author{
Maria Helena Prado de Mello Jorge, Vilma Pinheiro G awryszewski e Maria do Rosário D. \\ de $\mathbf{0}$. Latorre \\ Departamento de Epidemiologia da Faculdade de Saúde Pública da Universidade de São Paulo. São \\ Paulo, SP - Brasil (M. H. P. M. J., M. R. D. O. L.), Secretaria de Estado da Saúde de São Paulo. São \\ Paulo, SP - Brasil (V.P.G.)
}

\begin{abstract}
Resumo
As mortes por causas externas correspondem a grande parcela de óbitos em, praticamente, todos os países do mundo, ocupando, sempre, a segunda ou terceira colocação. Porém a sua distribuição quanto ao tipo de causa é diversa. Com o objetivo de estudar a mortalidade por causas externas, segundo o tipo de causa, sexo e idade, foi descrita a situação dessas mortes no Brasil e capitais, no período 1977 a 1994. Foram calculados os coeficientes de mortalidade por causas externas e a mortalidade proporcional, utilizando os dados de mortalidade fornecidos pelo Sistema de Informação de Mortalidade do Ministério da Saúde, e a população foi estimada baseada nos dados censitários de 1970, 1980 e 1991. Os resultados mostraram que, em números absolutos, os óbitos por causas externas quase dobraram no período de 1977 a 1994, passando a ser a segunda causa de morte no País. O coeficiente de mortalidade, em 1994, foi de 69,8/ 100.000 habitantes e o maior crescimento se deu nos óbitos do sexo masculino. Os coeficientes de mortalidade masculinos são, aproximadamente, 4,5 vezes o valor dos femininos. As causas externas representaram a primeira causa de morte dos 5 aos 39 anos, sendo a maior ocorrência na faixa etária dos 15 a 19 anos (65\% dos óbitos por causas externas). Além do aumento, parece estar ocorrendo um deslocamento das mortes para faixas etárias mais jovens. A mortalidade por causas externas, segundo tipo, mostra que durante o período analisado houve aumento tanto nos óbitos por acidentes de trânsito, quanto por homicídios, tendo os suicídios permanecido, praticamente, constantes. No grupo de acidentes classificados como "demais acidentes" houve leve aumento, devido, principalmente, às quedas e afogamentos. Nas capitais dos Estados a mortalidade por causas externas apresentam valores mais altos que a média brasileira, com exceção de algumas áreas do Nordeste. As capitais da região Norte apresentaram algumas das maiores taxas para o País. Já na região Nordeste apenas Recife, Maceió e Salvador apresentaram níveis muito elevados em relação ao País. Vitória, Rio de Janeiro e São Paulo, na região Sudeste, apresentaram os maiores coeficientes do País e Belo Horizonte apresentou declínio no período de estudo. Na região Sul houve aumento nas taxas, bem como na região Centro-Oeste, que teve aumento homogêneo em suas capitais. Esse aumento observado nas diferentes capitais apresentou diferenciais quanto ao tipo de causa externa. Os suicídios não representaram problema de Saúde Pública em nenhuma delas. Os acidentes de trânsito em Vitória, Goiânia, Macapá, Distrito Federal e Curitiba tiveram sua situação agravada. Os homicídios tiveram au-
\end{abstract}


mento expressivo em Porto Velho, Rio Branco, Recife, São Luís, Vitória, São Paulo, Curitiba, Porto Alegre, Cuiabá e Distrito Federal. No período estudado houve o crescimento da importância das causas externas para a população brasileira, chamando atenção, principalmente, o aumento dos homicídios. A qualidade das estatísticas de mortalidade por causas externas depende da colaboração do médico legista, e essa qualidade não é a mesma para todas as capitais estudadas.

Causa da morte, tendências. Coeficiente de mortalidade.

\section{Abstract}

External causes are an important cause of death in almost all countries. They are alw ays the second or third in the mortality ranking, but their distribution according to type varies from country to country. Mortality due to external causes by type, gender and age, for Brazil as a whole and for state capitals specifically, is analysed. Mortality rates and the proportional mortality from 1977 to 1994 were calculated. The results showed that the number of deaths due to external causes has almost doubled from 1977 to 1994 and nowadays this is the second cause of death in Brazil. The mortality rate, in 1991, was 69.8 per 100,000 inhabitants and the highest increase was in the male rates. The male rates are almost 4.5 times greater than the female ones. The first cause of death among people from 5 to 39 years old is external causes, and the majority occur betw een 15 and 19 years of age (65\% of the deaths by external causes). Besides the growth in itself it also seems that a shift of deaths to hower ages is occurring. Both mortality by traffic accidents and that by homicide have increased over the period from 1977 to 1994. Suicides have been stable and "other external causes" have increased slowly, especially due to falls and drowning. The mortality rates for external causes in state capitals are higher than the average for Brazil as a whole, except for some northeastern capitals. The rates for the capitals in the northern region are the highest in Brazil. In the northeastern region, only Recife, M aceió and Salvador have high rates. In the southeast, Vitória, Rio de Janeiro and S. Paulo have the highest rates in the country but Belo Horizonte's rates are declining. In the southern region all the capitals showed a growth in the rates as also in the capitals of the West-central region. The growth of mortality due to external causes type of external cause is different in these capitals. Suicide is not a public health problem in Brazil nor the state capitals. Traffic accidents are a major problem in Vitória, G oiânia, Macapá, the Distrito Federal and Curitiba. Homicides have increased greatly in Porto Velho, Rio Branco, Recife, S. Luís, Vitória, S. Paulo, Curitiba, Porto Alegre, Cuiabá and the Distrito Federal. The mortality due to external causes in Brazil has become a major public health problem, especially because of homicides. It is important to emphasize that the quality of the mortality data on external causes is not the same for all capitals, because it is a question very closely related to the quality of legal information.

\section{Cause of death. Mortality rate.}




\section{1 - PRELIMIN ARES}

\section{O Sistema de Informação de Mortalidade do Ministério da Saúde}

No Brasil, até bem pouco tempo, toda a informação relativa aos óbitos era de responsabilidade da Fundação IBGE. Hoje, os dados de mortalidade advêm de um sistema montado pelo Ministério da Saúde, em 1975, e que vem se aperfeiçoando, desde então. O Sistema de Informação de Mortalidade (SIM/MS) teve início com a implantação, em nível nacional, de um modelo padronizado de atestado de óbito. Esse, uma vez preenchido pelo médico (ou perito-legista, no caso de mortes por causas não naturais) deve ser levado ao Cartório de Registro Civil, de onde os dados são recolhidos periodicamente, por órgãos estaduais, que os digitam e analisam, remetendo-os, posteriormente, ao Ministério da Saúde para publicação do consolidado nacional. Esse sistema engloba, atualmente, cerca de $80 \%$ dos óbitos totais do País, estimados, por métodos indiretos, em cerca de um milhão/ano. Escapam ao sistema cerca de $20 \%$ dessas mortes, tanto em razão de não serem registradas, como do fato de, por motivos diversos, algumas localidades não estarem ainda enviando as informações ao Ministério, de modo regular. Esses dados estão disponíveis para o Brasil como um todo, Estados e capitais, segundo sexo, idade e causa, de acordo com a Classificação Internacional de Doenças, adaptação para o Brasil (Mello Jorge ${ }^{19}$, 1993).

Afeta ainda a qualidade desses dados, o número, por vezes, grande, de mortes por "sintomas e estados mórbidos maldefinidos" ou, simplesmente, os óbitos em que não houve assistência médica, e a causa é, portanto, desconhecida.

Especificamente com relação às causas externas, a Declaração de Óbito constitui-se em boa fonte de informação do ponto de vista quantitativo, mas apresenta algumas falhas quanto à sua qualidade, pela seguinte razão: na parte internacional do modelo da Declaração de Óbito (atestado médico) local destinado à colocação das causas de óbito os legistas, após necropsia, às vezes, em número não pequeno de casos, fazem menção à natureza das lesões que levam à morte sem se referirem aos tipos de acidentes/violência que ocasionaram essas lesões. As regras internacionais existentes para o preenchimento dos atestados determinam que, nesses casos, como já foi visto, devam ser colocados os dois tipos de informações (Laurenti e Mello Jor$\left.\mathrm{ge}^{14}, 1987\right)$. É esse o motivo pelo qual vão ocorrer óbitos por "causas externas de tipo ignorado", para algumas áreas, em quantidade não desprezível. Esse fato prejudica o estudo das mortes por acidentes e violências de vez que, somente conhecendo a ocorrência/distribuição de cada um de seus tipos, será possível preveni-los.

\section{2 - O BJETIVO}

O objetivo desta primeira parte é estudar a mortalidade por causas externas em seus principais aspectos epidemiológicos, descrevendo a situação dessas mortes no Brasil e capitais de Estado, no período 1977 a 1994, segundo algumas variáveis consideradas importantes desse ponto de vista.

\section{3 - MATERIAL E MÉTO DO}

O material de estudo diz respeito à totalidade de óbitos por causas externas captadas pelo SIM/MS. As Unidades da Federação e Ministério da Saúde utilizam-se de conceitos, definições e regras internacionais de codificação de causa de morte (OMS, 1979), e a apresentação dessas estatísticas é feita sempre, segundo local de residência.

\section{Áreas Trabalhadas}

- Brasil - o País é estudado como um todo, apesar de certa limitação apresentada pelos dados.

- Capitais das Unidades da Federação e Distrito Federal por se considerar que a informação, em nível estadual, deixa a desejar (algumas áreas têm baixa cobertura, elevado sub-registro de óbitos e grande número de mortes por causas maldefinidas, além de alto percentual de causas externas de tipo ignorado). É pressuposto que alguns desses problemas ocorram em menor número nos municípios das capitais (Mello Jorge ${ }^{19}, 1993$ ).

\section{Período de Referência}

- 1977 a 1994: Estatísticas de Mortalidade. Brasil, dados já publicados (Ministério da Saúde $\left.{ }^{21}, 1979 / 97\right)$.

\section{Variáveis}

As mortes são estudadas segundo sexo, idade e tipo de causa, sendo apresentadas segundo a CID-9 (OMS 22,1980$)$, agrupando-as em: acidentes de trânsito de veículos a motor (E810 a E819); demais acidentes (E800 a 809 e E820 a E949), suicídios e lesões auto-inflingidas (E950 a E959); homicídios e intervenções legais (E960 a 969 e E970 a E979) e ignorado (E980 a E989); em conjunto E800 a E999.

\section{População}

Para o cálculo dos coeficientes, são utilizadas estimativas de população obtidas por interpolação linear — Método de Lagrange - a partir dos dados dos censos de 1970, 1980 e 1991 fornecidos pela Fundação $\operatorname{IBGE}^{10,11,12}$ (1973, 1982 e 1993).

\section{Medidas}

Foram utilizadas a mortalidade proporcional e coeficientes de mortalidade por causas externas. 


\section{RESULTAD OS E DISCUSSÃO}

\subsection{As Causas Externas no Tempo}

A Tabela 1 mostra as mortes por causas externas, no País, em números absolutos, mortalidade proporcional e coeficientes de mortalidade no período compreendido entre 1977 e 1994. Em 1977 as causas externas fizeram 55.240 vítimas fatais e, em 1994, 107.292 mortes. Em números absolutos, esses óbitos quase que dobraram, enquanto que o mesmo não ocorreu com o crescimento populacional no período, o que já evidencia a importância que vem assumindo esta mortalidade para a população brasileira.

Nos dezoito anos que compõem esta série, verifica-se que o número de óbitos é sempre crescente e que o peso dessas mortes em relação à mortalidade total cresce de importância a cada ano, revelando, em 1994, aumento de praticamente 40,0\% em relação a 1977. Esse aumento da mortalidade proporcional por causas externas é melhor visualizado na Figura 1, que mostra, para três pontos do período estudado, este crescimento: em 1977, representou $8,7 \%$ do total de mortes, passando para $10,2 \%$, em 1984 e chegando, em 1994, a 12,0\%, sendo que, quando calculadas sobre o total de mortes com causa definida, ultrapassam os $15 \%$. Nessa situação, as causas externas passam a se constituir no segundo grupo de causas de morte, apenas abaixo das doenças do aparelho circulatório.

Comparativamente a outros países da região das Américas (OPS $\left.{ }^{24}, 1994\right)$ o Brasil tem percentual semelhante ao do México, Nicarágua, Panamá e Venezuela (ao redor de 15\%), sendo que, somente na Colômbia esses números são mais elevados. Com relação aos Estados Unidos e Canadá, o valor apre-
Tabela 1: Número, proporção e coeficientes de mortalidade por causas externas. Brasil, 1977 a 1994

\begin{tabular}{cccc}
\hline Ano & No & $(\%)^{*}$ & $\begin{array}{r}\text { Coef. M ort. } \\
100.000 \text { hab. }\end{array}$ \\
\hline 1977 & 55.240 & 8,7 & 49,9 \\
1978 & 59.683 & 9,0 & 52,7 \\
1979 & 65.253 & 9,2 & 56,3 \\
1980 & 70.212 & 9,4 & 59,0 \\
1981 & 71.833 & 9,6 & 59,4 \\
1982 & 73.460 & 9,9 & 59,5 \\
1983 & 78.008 & 10,1 & 61,9 \\
1984 & 82.386 & 10,2 & 64,1 \\
1985 & 85.845 & 10,9 & 65,5 \\
1986 & 95.968 & 11,8 & 71,8 \\
1987 & 94.421 & 11,8 & 69,3 \\
1988 & 96.174 & 11,5 & 69,4 \\
1989 & 102.252 & 12,5 & 72,4 \\
1990 & 100.656 & 12,3 & 70,0 \\
1991 & 102.023 & 12,0 & 69,5 \\
1992 & 98.944 & 12,0 & 66,5 \\
1993 & 103.751 & 11,8 & 68,6 \\
1994 & 107.292 & 12,0 & 69,8 \\
\hline
\end{tabular}

* Percentuais calculados sobre o total de mortes por todas as causas

sentado pelo Brasil corresponde, praticamente, ao dobro do verificado nesses países. E o mesmo pode ser observado quando são analisados os dados de mortalidade de alguns países europeus, tais como Espanha, Suécia e Portugal $\left(\mathrm{OMS}^{23}, 1994\right)$. É claro que a mortalidade proporcional mede somente a importância relativa desse tipo de causa, estando relacionada, por exemplo, com a queda das mortes por outras causas, cujo declínio, por si só, faria com que aumentasse a importância relativa das causas externas.

Em relação aos coeficientes de mortalidade, o aumento verificado é da ordem de quase $40 \%$, saindo de 49,9/100.000 habitantes, em 1977, chegando a
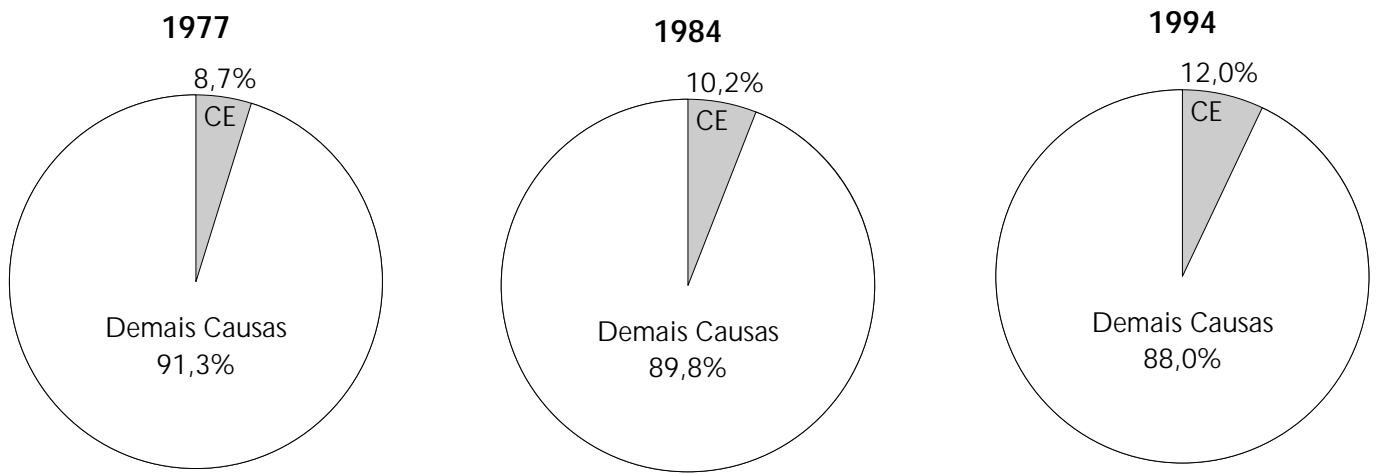

Figura 1 - Mortalidade proporcional por causas externas (CE). Brasil, 1977, 1984 e 1994. 


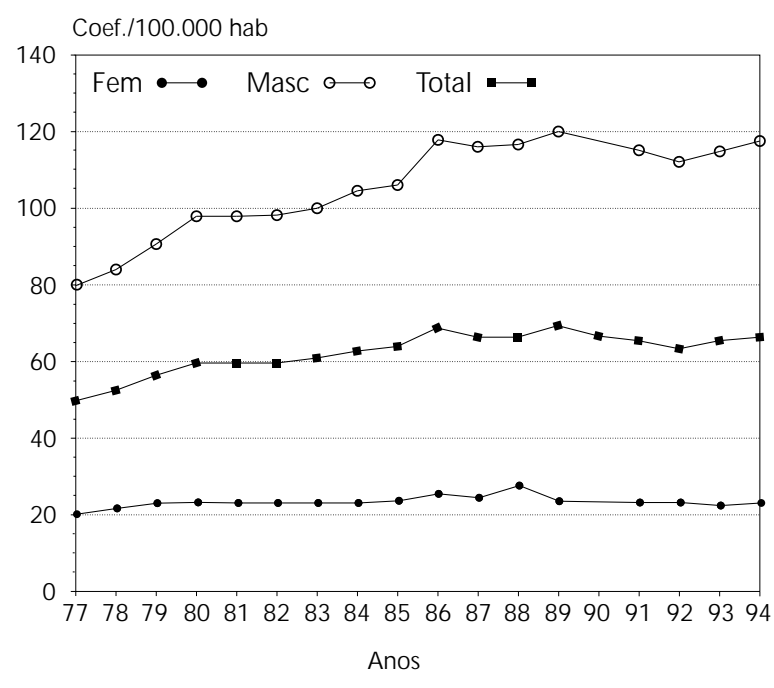

Figura 2 - Coeficientes de mortalidade por causas externas segundo sexo. Brasil, 1977 a 1991.

69,8/100.000 habitantes, em 1994. A Figura 2 mostra a curva construída para esse período, onde pode ser observado o crescimento gradual desses coeficientes, também segundo sexo. Essa elevação se deu de forma diferenciada nos homens e nas mulheres, atingindo principalmente o sexo masculino, cujo aumento foi de $47,2 \%$, enquanto que o do sexo feminino foi de $15,7 \%$.

Em recente estudo sobre mortalidade por causas externas na região das Américas, Yunes e Rajs ${ }^{29}$ (1994) concluíram que a mortalidade por essas causas apresentava uma tendência de queda na população de um modo geral (do estudo participaram 15 países, representando $87 \%$ da população da Região), no período entre 1979 e 1990, sendo que só três países apresentaram tendências francas de crescimento: Brasil, Colômbia e Cuba.

A comparação dos coeficientes de mortalidade por causas externas, apresentados pelo Brasil, com os relativos aos demais países americanos, mostra que essas taxas são das mais elevadas, embora bastante abaixo daquela apresentada por El Salvador, no ano de 1986, (125,7/100.000) e muito acima das taxas da Jamaica, apenas 19,3/100.000 habitantes (Yunes ${ }^{28}, 1993$ ). Alguns países, que no início dos anos 80 apresentavam taxas maiores que as brasileiras, chegaram ao final da década com taxas quase iguais, como por exemplo o México.

A análise das taxas globais para o Brasil mostra que essa mortalidade se comporta diferentemente, segundo sexo, idades das vítimas, tipo de acidente ou violência e regiões geográficas.

\subsection{Características Pessoais das Vítimas}

Borbeau ${ }^{4}$ (1993), trabalhando com mortalidade por causas externas para vários países, para os anos de 1985 a 1989, a partir dos valores assumidos pelos coeficientes em cada sexo, propõe classificá-la em forte, intermediária e fraca. Os números do Brasil, já no início da série estudada, expressos na Figura 2, para o sexo masculino, nunca o colocaram numa situação classificada como de mortalidade fraca: o País já saiu de 1977 com taxas nos níveis de mortalidade intermediária. No início da década de 80, esses coeficientes já vão passando para forte, podendo ser classificada desse modo a partir de 1985. Diferentemente, para o sexo feminino, esta mortalidade pode ser classificada, durante todo o período estudado, como fraca passando para intermediária.

Na Tabela 2 são apresentados os óbitos por causas externas, segundo sexo e faixa etária, em números absolutos, percentuais e coeficientes de mortalidade para dois pontos da série, anos de 1984 e 1994.

Tomando os valores dos coeficientes de cada um dos sexos, nesses dois momentos, verifica-se uma sobremortalidade masculina bastante acentuada (coeficientes iguais a 105 e 116/100.000 homens e 23 e 24/ 100.000 mulheres), mostrando que o sexo masculino corresponde a, aproximadamente, 4,5 vezes o valor do feminino. A razão entre esses valores variou entre um mínimo de 3,7, em 1977, e um máximo de 5,0 (1989). Yunes ${ }^{28}$ (1993) centra a explicação desse fenômeno no fato de a mulher estar menos inserida no mercado de trabalho, afirmando que quanto mais ela participa da força de trabalho mais exposta se encontra ao risco de acidentes e, portanto, menores são as diferenças apresentadas. A ser verdadeira esta afirmação, fica difícil entender o que acontece no Município de São Paulo onde série histórica de mortalidade por essas causas, de 1960 a 1980 (Mello Jorge ${ }^{16,17}, 1979$ e 1982), mostrou que a razão esteve ao redor de 3,5, e novo estudo, para 1991 (Gawryszewski $\left.{ }^{8}, 1995\right)$ evidenciou que a razão entre os coeficientes masculino e feminino cresceu, sendo de 6,4 quando, provavelmente, a participação feminina no mercado de trabalho também deve ter crescido.

Com relação às idades, importante colocação a ser feita diz respeito ao peso dos acidentes/violências no total de mortes de cada faixa etária, como pode ser visto na Figura 3, para 1981 e 1991.

Os acidentes e violências constituem-se no primeiro grupo de causas de morte, desde os 5 anos até os 39 anos, sendo que na faixa dos 15 aos 19 anos foram responsáveis por, praticamente, $65 \%$ do 
Tabela 2 - M ortalidade por causas externas segundo sexo e idade (no, \% e coeficientes/100.000 habitantes). Brasil, 1984 e 1994.

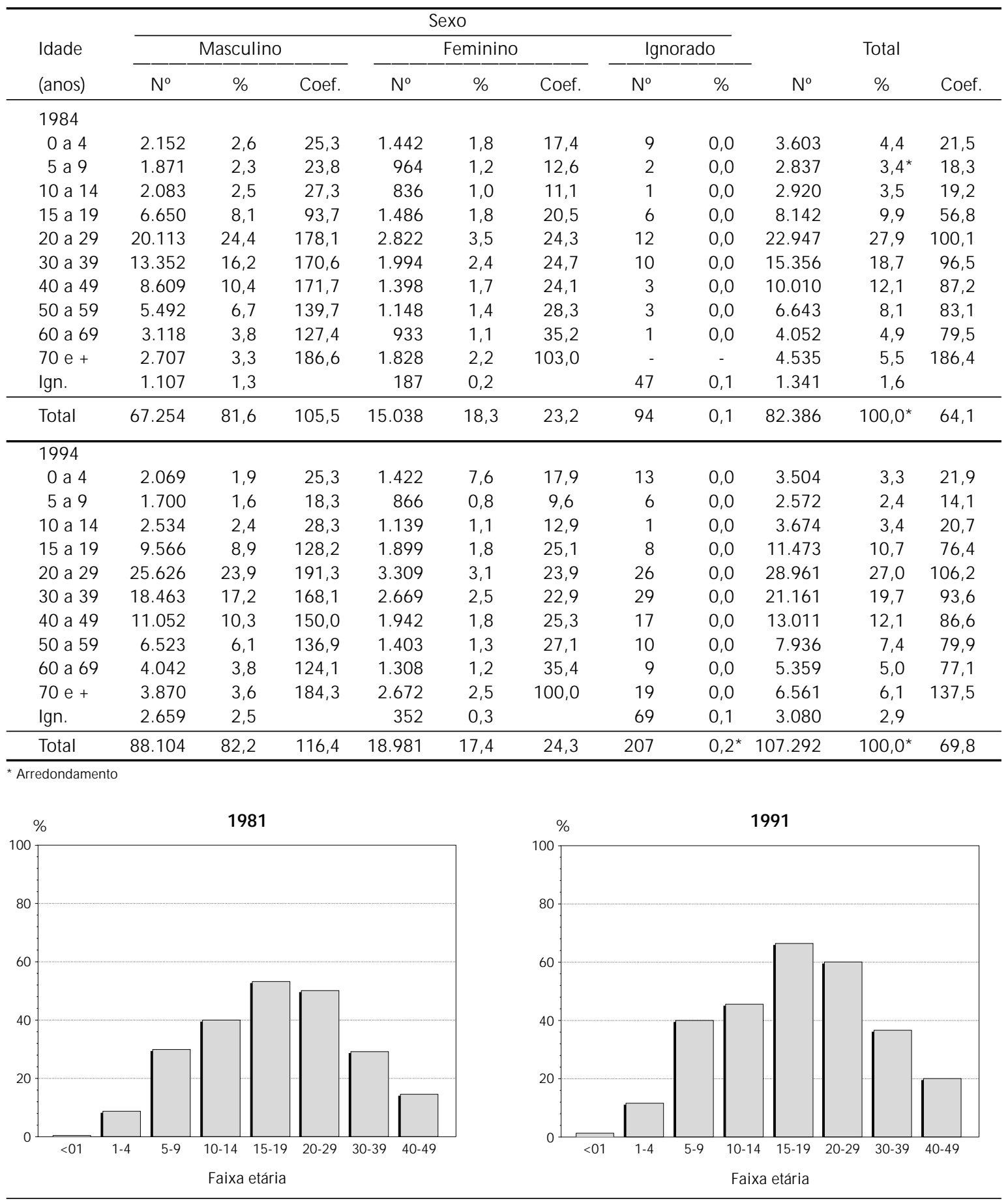

Figura 3 - Mortalidade proporcional por causas externas segundo faixas de idade. Brasil, 1981 e 1991.

de óbitos e, na de 20, a 29, 59\%, em 1991. De 1981 a 1991 houve aumento dessa representatividade em todos os grupos etários apresentados na Figura 3, sendo que, entre os menores de um ano, o peso das causas externas, embora com percentual bastante baixo, teve seu incremento mais visível (160\%). Na faixa de 1 a 4 anos o aumento foi de $76 \%$. Na análise desses valores para as capitais brasileiras, podese verificar, em algumas delas (tal como o Distrito Federal), que desde a faixa de 1 a 4 anos essas cau- 
sas já despontam em primeiro lugar. Os dados do Município de São Paulo, para o ano de 1991, mostram que a sua mortalidade proporcional por causas externas é ainda mais acentuada que a média brasileira para as faixas mais jovens, pois já na faixa de 5 a 9 anos, esse percentual chega a $42 \%$, na de 10 a 14 anos é de $60,8 \%$, e para os de 15 a 19 anos chegam a $79,0 \%$. A partir destas faixas os percentuais apresentam-se bastante semelhantes aos do Brasil como um todo (Fundação Seade ${ }^{12}$, 1992, dados brutos).

Ao se analisar as taxas específicas por idade e sexo, verifica-se aumento a partir dos 15 anos, no sexo masculino, nos dois momentos estudados (1984 e 1994). A principal diferença apresentada entre esses dois anos está no fato de que, entre os homens, em 1984, as taxas bastante semelhantes nas idades de 20 a 49 anos declinaram nas faixas de 50 a 59 anos e subiram para um patamar mais alto nos homens com 70 anos e mais. Em 1994, embora as idades mais avançadas tenham ainda coeficientes altos, é no grupo de 20 a 29 anos onde estão localizados os valores mais elevados. Para o sexo feminino, embora nas idades mais jovens (10 a 19) seja observado um aumento nesses coeficientes, não há picos acentuados; eles vão ocorrer nos grupos de idade mais velhos. Pode-se supor que, além do aumento, esteja havendo um deslocamento das mortes por causas externas para faixas etárias mais jovens, já que a de 15 a 19 anos, no sexo masculino, por exemplo, pas- sou de 93,7 para 128,2 ; a de 20 a 29 anos, de 178,1 para 191,3 e, assim, sucessivamente. Esse deslocamento também já foi citado por Souza ${ }^{26}$ (1994), relativamente aos homicídios e é reforçado na parte III do presente trabalho.

Este padrão de distribuição segundo sexo e idade, com maiores coeficientes no sexo masculino, nas idades mais jovens e nas mais avançadas, também é observado em vários outros países tais como a Itália, Alemanha, Israel $\left(\mathrm{OMS}^{23}, 1994\right)$; porém, nas idades mais avançadas, os coeficientes são ainda maiores que aqueles observados no Brasil, e as taxas femininas se sobrepõem às masculinas. Isto se deve aos altos coeficientes de mortalidade por quedas, que vão ocorrer nas populações velhas.

\subsection{As Causas Externas Segundo Tipo}

Em relação aos tipos de causas que compõem a mortalidade por causas externas, a Tabela 3 mostra os números absolutos e os coeficientes para o período estudado. Na Figura 4 pode ser visualizado o comportamento desses coeficientes.

Verifica-se que os acidentes de trânsito exibem coeficientes que podem ser considerados altos, durante todo período. $\mathrm{O}$ crescimento observado entre 1977 e 1994 é de 17,4\%. Os países desenvolvidos exibem tendência inversa no mesmo período, revelando as conseqüências de investimentos feitos no setor (Beeck e col. ${ }^{3}$, 1991) em relação à segurança dos carros, das estradas e outras (obrigatoriedade do

Tabela 3 - M ortalidade por causas externas segundo tipo (no e coeficiente por 100.000 habitantes). Brasil, 1977 a 1994.

\begin{tabular}{|c|c|c|c|c|c|c|c|c|c|c|c|}
\hline \multirow[t]{2}{*}{ Ano } & \multicolumn{2}{|c|}{ Ac. Trâns } & \multicolumn{2}{|c|}{ D emais AC. } & \multicolumn{2}{|c|}{ Suicídios } & \multicolumn{2}{|c|}{ Homicídios } & \multirow{2}{*}{$-\frac{\operatorname{lgn}}{\mathrm{N}} \frac{\mathrm{o}}{\mathrm{O}}$} & \multicolumn{2}{|c|}{ Total } \\
\hline & No & Coef. & No 0 & Coef. & No & Coef. & $\mathrm{N}=$ & Coef. & & $\mathrm{N} 0$ & Coef. \\
\hline 1977 & 17.795 & 16,1 & 16.541 & 14,9 & 3.525 & 3,2 & 8.715 & 7,9 & 8.664 & 55.240 & 49,9 \\
\hline 1978 & 19.967 & 17,0 & 15.985 & 14,1 & 3.255 & 2,9 & 9.146 & 8,1 & 11.330 & 59.683 & 52,7 \\
\hline 1979 & 20.825 & 18,0 & 16.234 & 14,0 & 3.490 & 3,0 & 11.194 & 9,7 & 13.510 & 65.253 & 56,3 \\
\hline 1980 & 19.851 & 16,7 & 21.001 & 17,6 & 3.896 & 3,3 & 13.910 & 11,7 & 13.554 & 70.212 & 59,0 \\
\hline 1981 & 19.161 & 15,8 & 21.157 & 17,5 & 4.0 .61 & 3,4 & 15.213 & 12,6 & 12.241 & 71.833 & 59,4 \\
\hline 1982 & 20.755 & 16,8 & 20.436 & 16,6 & 3.917 & 3,2 & 15.550 & 12,6 & 12.802 & 73.460 & 59,5 \\
\hline 1983 & 20.077 & 15,9 & 24.781 & 19,7 & 4.586 & 3,6 & 17.408 & 13,8 & 11.226 & 78.008 & 61,9 \\
\hline 1984 & 21.942 & 17,1 & 23.407 & 18,2 & 4.433 & 3,5 & 19.767 & 15,4 & 12.837 & 82.386 & 64,1 \\
\hline 1985 & 24.298 & 18,5 & 23.898 & 18,2 & 4.256 & 3,2 & 19.747 & 15,1 & 13.646 & 85.845 & 65,5 \\
\hline 1986 & 29.574 & 22,1 & 25.820 & 19,3 & 4.313 & 3,2 & 20.479 & 15,3 & 15.782 & 95.968 & 71,8 \\
\hline 1987 & 27.611 & 20,3 & 24.846 & 18,2 & 4.701 & 3,5 & 23.087 & 17,0 & 14.176 & 94.421 & 69,3 \\
\hline 1988 & 27.942 & 20,1 & 25.430 & 18,3 & 4.492 & 3,2 & 23.357 & 16,8 & 14.952 & 96.173 & 69,4 \\
\hline 1989 & 28.839 & 20,4 & 26.439 & 18,7 & 4.491 & 3,2 & 28.757 & 20,4 & 13.726 & 100.252 & 72,4 \\
\hline 1990 & 28.470 & 19,8 & 26.360 & 18,3 & 4.845 & 3,4 & 31.989 & 20,9 & 8.992 & 100.656 & 70,0 \\
\hline 1991 & 27.866 & 19,0 & 27.623 & 18,0 & 5.186 & 3,5 & 30.750 & 20,9 & 10.578 & 102.023 & 69,5 \\
\hline 1992 & 26.627 & 17,9 & 25.941 & 17,4 & 5.259 & 3,5 & 28.374 & 19,1 & 12.743 & 98.944 & 66,5 \\
\hline 1993 & 27.289 & 18,0 & 26.464 & 17,5 & 5.555 & 3,7 & 30.610 & 20,2 & 13.833 & 103.751 & 68,6 \\
\hline 1994 & 29.014 & 18,9 & 26.939 & 17,5 & 5.932 & 3,9 & 32.603 & 21,2 & 12.804 & 107.292 & 69,8 \\
\hline
\end{tabular}




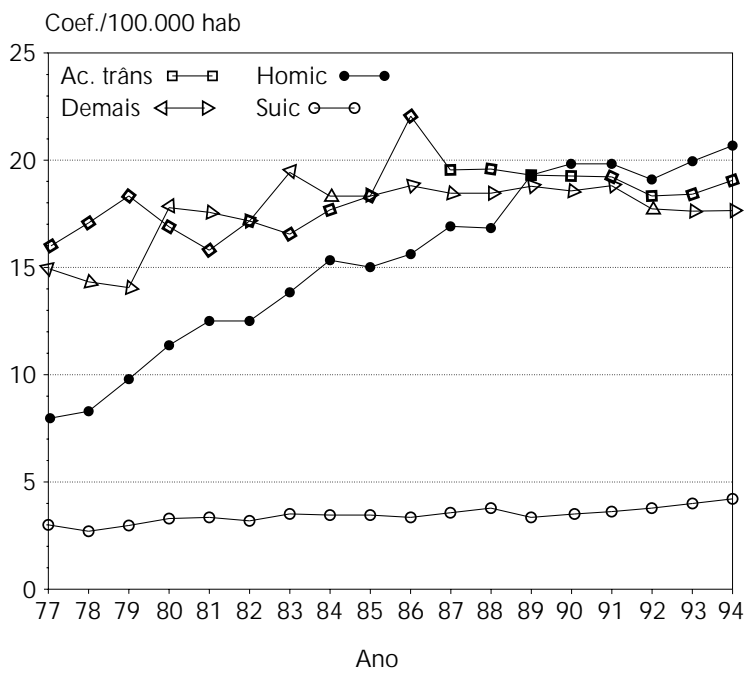

Figura 4 - Coeficientes de mortalidade por causas externas segundo tipo de causa. Brasil, 1977 a 1994.

uso de cinto de segurança, limitação da velocidade, maior fiscalização no uso de álcool, entre outros). O "Center for Disease Control" (1992) refere que as taxas de mortalidade por acidentes de trânsito nos Estados Unidos vem declinando substancialmente desde 1966.

Em números absolutos, as mortes por acidentes de trânsito passaram de 17.795 para 29.014, em 1994. Percentualmente, em relação ao total de causas externas, mantiveram-se ao redor de $31 \%$, e quanto aos coeficientes, analisados globalmente para os dois sexos, os valores estiveram em alta de 1985 a 1989 (Mello Jorge e Latorre ${ }^{20}, 1994$ ), iniciando queda a partir de 1990. Até 1984 os coeficientes mantiveramse ao redor de 17, chegando a atingir 22 em 1986, sendo que em 1994 foi próximo a 19,0, todos medidos por 100.000 habitantes. Os coeficientes no sexo masculino representaram, aproximadamente, três vezes os do sexo feminino, e os óbitos ocorreram no adulto jovem, fato que evidencia grande perda na população economicamente ativa, de grande peso para áreas em desenvolvimento. A Figura 5 mostra esses coeficientes segundo sexo e idade para o País como um todo, em 1984 e 1994.

Observa-se que nos dois anos estudados os coeficientes do sexo masculino saltam a partir da faixa dos 15 a 19 anos, mantendo-se em níveis elevados nas idades subseqüentes, dando outro salto a partir dos 70 anos. No sexo feminino, eles sobem gradativamente, com exceção da faixa de 10 a 14 anos, apresentando um forte aumento apenas na faixa de 70 anos e mais. Os coeficientes do ano de 1994 apresentam-se superiores aos de 1984, para todas as idades a partir dos dez anos, em ambos os sexos.

Os diferentes tipos de acidentes de trânsito constituem um orientador fundamental para a definição de políticas de prevenção destas mortes, visto que o estabelecimento de medidas voltadas para a diminuição dos atropelamentos, por exemplo, devem ser diversas daquelas dirigidas para a prevenção dos óbitos e ferimentos decorrentes das colisões de veículos. No entanto, esta avaliação é prejudicada pela

\section{Masculino}

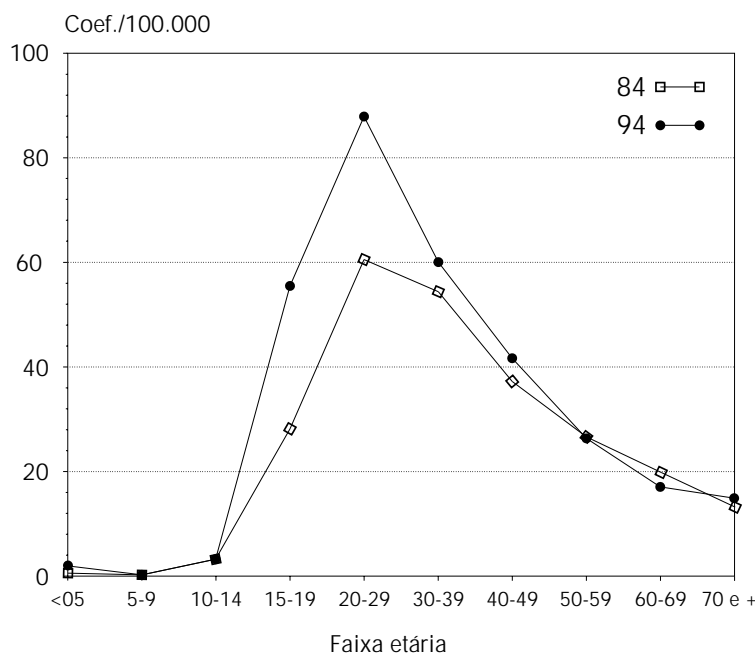

Feminino

\section{Coef./100.000}

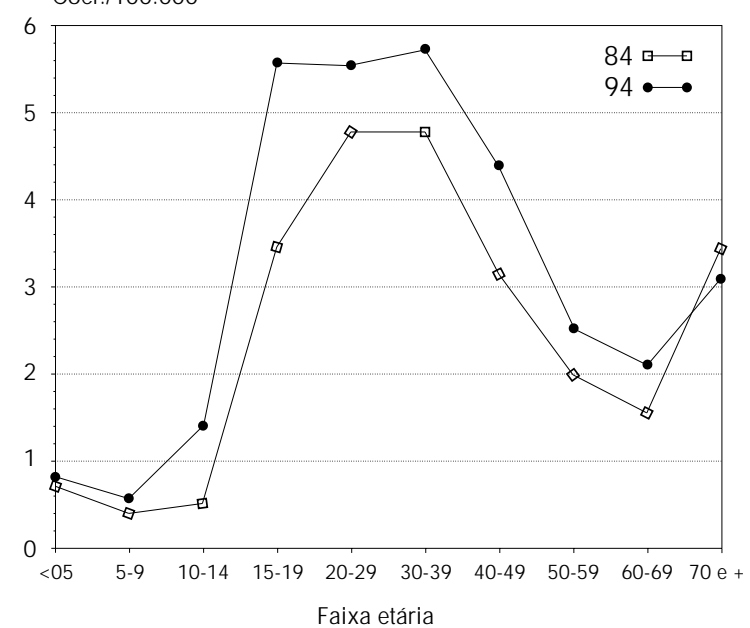

Figura 5 - Coeficientes de mortalidade por acidentes de trânsito segundo sexo e faixa etária. Brasil, 1977 a 1994. 
má qualidade da informação, na medida em que inexiste a especificação do tipo de acidente na Declaração de Óbito, preenchida pelo legista. Mello Jorge e Latorre ${ }^{20}$ (1994) chamaram atenção para esse fato, salientando que dados do Brasil, para o período de 1977 a 1987, mostraram que 70\% desses acidentes não estavam especificados, inviabilizando estudos que permitiriam o conhecimento de alguns aspectos epidemiológicos das mortes desse grupo. No entanto, para algumas áreas que, quanto a este aspecto, apresentavam melhor qualidade da informação, foi possível verificar a importância dos atropelamentos, que representaram sempre mais de $50 \%$ dessas mortes, chegando até $85 \%$ para o Município do Rio de Janeiro. As citadas autoras apontaram, ainda, que dada a importância desta informação para prevenção dessas mortes, seria necessário investir na melhoria de sua qualidade junto aos Institutos Médico-Legais do País. No Município de São Paulo, estudos realizados (Mello Jorge ${ }^{16,18}, 1979,1988$ ) mostram que essas instituições dispõem de um maior número de informações, que permitiriam melhor esclarecimento da causa básica de morte, pois possuem cópias do Boletim de Ocorrência Policial referentes aos casos, ou outros dados da investigação policial. Mas, geralmente, os legistas não as transcrevem na Declaração de Óbito, talvez devido ao temor de implicações legais.

O grupo dos "Demais acidentes" tem coeficientes de mortalidade em leve ascensão. Neste conjunto há que se considerar as diferentes causas de morte nele incluídas. Em termos de freqüência são importantes as quedas e os afogamentos, fato em que se baseou o próprio Ministério da Saúde ao elaborar a Classificação Internacional de Doenças, adaptada para o Brasil (CID-BR) (Ministério da Saúde ${ }^{21}$, 1993). Para o Município de São Paulo, estudos revelam que os principais componentes desse grupo são também as mortes decorrentes de afogamentos (atingindo sobretudo as faixas mais jovens) e de quedas (atingindo principalmente as faixas mais velhas) (Mello Jorge $^{16,17,18}$, 1979, 1982 e 1988; Gawryszewski $\left.^{8}, 1995\right)$. Para a maioria dos países europeus, são as quedas o componente predominante desse grupo $\left(\mathrm{OMS}^{23}, 1994\right)$, atingindo os indivíduos mais velhos.

Em relação à mortalidade por quedas, é necessário seu estudo quanto às diferentes faixas etárias, pois o esperado é a sua ocorrência em idades mais avançadas, por razões fisiológicas. Esses óbitos, entre os mais jovens, podem encobrir mortes devidas a acidentes de trabalho. Machado e Minayo ${ }^{15}$ (1994) apontam, em relação à freqüência de casos de acidente de trabalho, que a construção civil parece ser a ativida- de mais crítica o que, por via de conseqüência, mostra a relevância das quedas na idade adulta. Os fatores que concorrem para a possível subestimação desses acidentes podem, entre outros, decorrer da falta de anotação, na Declaração de Óbito, do fato de a morte ser devida a acidente de trabalho. Uma outra possibilidade pode ser a falta de registro profissional dos trabalhadores da construção civil que, de um modo geral, concentra operários pela baixa qualificação, fazendo com que mesmo nas Comunicações de Acidentes de Trabalho (que seria uma outra fonte para o conhecimento da dimensão desses óbitos) essas mortes não apareçam.

Com relação à distribuição das mortes acidentais, com exceção do grupo de acidentes de trânsito, nos dois sexos, as taxas em 1994 foram iguais a 29,6 por 100.000 homens e 8,1 por cem mil mulheres.

Os suicídios apresentaram coeficientes em torno de 3,5/100.000 habitantes, mantendo-se em níveis praticamente constantes durante todo o período estudado. Esses valores, embora se saiba subestimados, podem ser considerados baixos quando comparados com alguns países da Europa, cujos coeficientes se apresentam acima de 20/100.000 habitantes $\left(\mathrm{OMS}^{23}\right.$, 1994). Entretanto, se os suicídios não se mostram importantes em frequiência e se mantêm num patamar que pode ser considerado baixo, chamam a atenção por alguns aspectos. Em primeiro lugar, apresentam taxas mais elevadas em populações mais idosas, ocorrendo, entretanto, desde a adolescência. Neste grupo de idade, pode ser verificado, em estudo levado a efeito no Município de São Paulo, com metodologia de entrevistas com as famílias, que estas referiram que os jovens que morreram apresentavam sempre algum tipo de transtorno mental (Mello Jorge ${ }^{18}, 1988$ ), fato que alguns autores (Allgulander e Lavori ${ }^{1}, 1993$; Casedebaig e Philippe ${ }^{5}$, 1992) consideram estar sempre associado ao suicídio ou suas tentativas. Essa constatação reveste-se de grande importância quando se pensa em programas de prevenção, mostrando que, se prevenido ou tratado o transtorno mental do jovem, a consumação do suicídio pode se minimizar. Quando os dados são suficientes para a análise, verifica-se que os jovens consumam seus atos suicidas através de meios que não requerem qualquer premeditação. $\mathrm{Na}$ pesquisa referida (Mello Jorge ${ }^{18}$, 1988) o meio utilizado por esses jovens foi, em geral, a precipitação de lugar elevado.

Os coeficientes de mortalidade por suicídio são sempre maiores no sexo masculino contrariamente às tentativas, mais numerosas entre as mulheres do que homens. Cassorla e Smeke ${ }^{6}$ (1994) estimaram que a taxa dessas tentativas chegou a $152 / 100.000$ 
habitantes, para o Município de Campinas, São Paulo, no ano de 1982 , e que $75 \%$ dos casos atingiam a indivíduos menores de 27 anos.

Quanto aos homicídios, foram responsáveis por cerca de 30\% das mortes por causas externas, em 1994, ocupando o primeiro lugar dentre elas. Proporcionalmente às demais causas externas, foi em 1989 que o número de homicídios praticamente se igualou ao das mortes por acidentes de trânsito, passando, a partir de então, a ter maior representatividade. Os coeficientes de mortalidade por essa causa, que ocupavam o terceiro lugar no inicío do período (7,9/100.000 habitantes em 1977), chegam ao primeiro posto no começo da década de 90 , com aumento de mais de $160 \%$, tendência de crescimento que é verificada na maioria das capitais do País. Esse fenômeno, aliás, está ocorrendo também em outros países da América: Yunes e Rajs ${ }^{29}$ (1994) ressaltam que entre esses países, os homicídios são particularmente alarmantes na Colômbia, Brasil, México, Porto Rico e Venezuela, especialmente entre adolescentes e jovens. Nos Estados Unidos, que embora apresente aumento menor em suas taxas que aquele encontrado para o Brasil, os homicídios também são apontados como um grave problema, que atinge principalmente população masculina de afro-americanos, jovens (entre 15 e 19 anos) (Jeanneret e Sand ${ }^{13}$, 1993).

É neste tipo de causa que a sobremortalidade masculina tende a ser mais acentuada. Souza ${ }^{26}(1994)$, em relação aos coeficientes segundo sexo, afirma que os homens apresentam uma freqüência de homicí-

Feminino

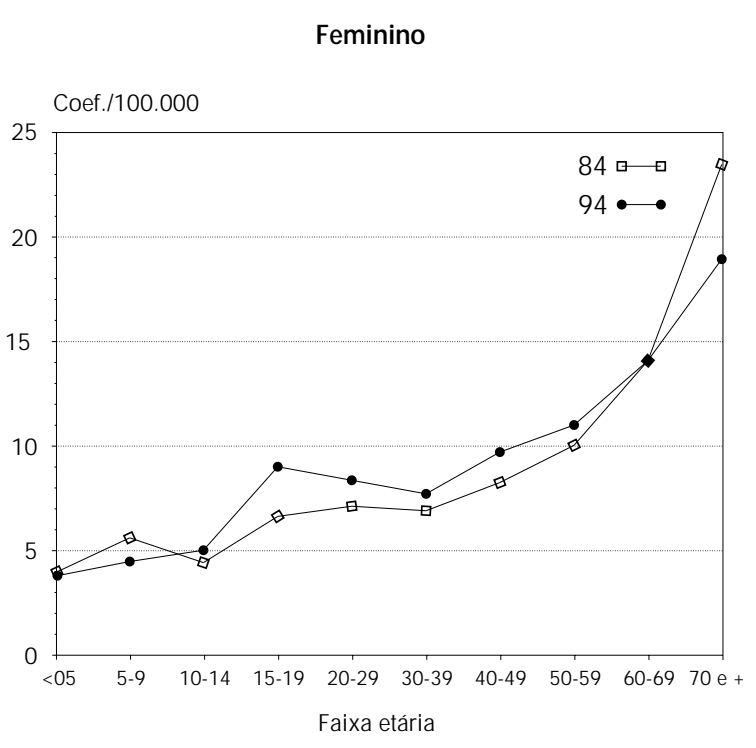

dios igual a dez vezes a das mulheres. Mello Jorge ${ }^{16}$ (1979) já mostrava essa relação nos coeficientes de mortalidade para o Município de São Paulo, desde 1960. Os dados para o Brasil, em 1994, registram que em algumas idades essa relação chega a ser 12 a 13 vezes (idades de 20 a 29 e 30 a 39). A Figura 6 mostra o comportamento desses coeficientes segundo sexo e idade, nos anos de 1984 e 1994.

Observa-se nestes dois pontos do período estudado que os maiores coeficientes pertencem às idades mais jovens, para o sexo masculino, de 15 a 49 anos, especialmente a faixa de 20 a 29 anos, cujas taxas foram cerca de 80 vezes maior que as da faixa de menores de 5 anos e 6 vezes as de 70 anos e mais, no ano de 1994. As taxas femininas mostram seus maiores valores também entre os mais jovens, embora em níveis mais baixos. A comparação entre essses dois anos evidencia que os coeficientes masculinos mostraram elevação em 1994, em quase todas as faixas de idade, e a faixa de 15 a 19 anos apresentou o maior crescimento percentual. Os coeficientes femininos também mostraram-se mais elevados em 1994, sem revelar, no entanto, crescimento acentuado como o do sexo masculino.

A análise dos dados referentes a 1994, último ano da série, para o Brasil, em relação aos diferentes tipos de causa, evidencia situação bastante diferente daquela apresentada pelos países desenvolvidos (Tabela 4), onde a composição da mortalidade violenta é representada principalmente pelo componente não intencional (com predomínio da mortalidade por acidentes

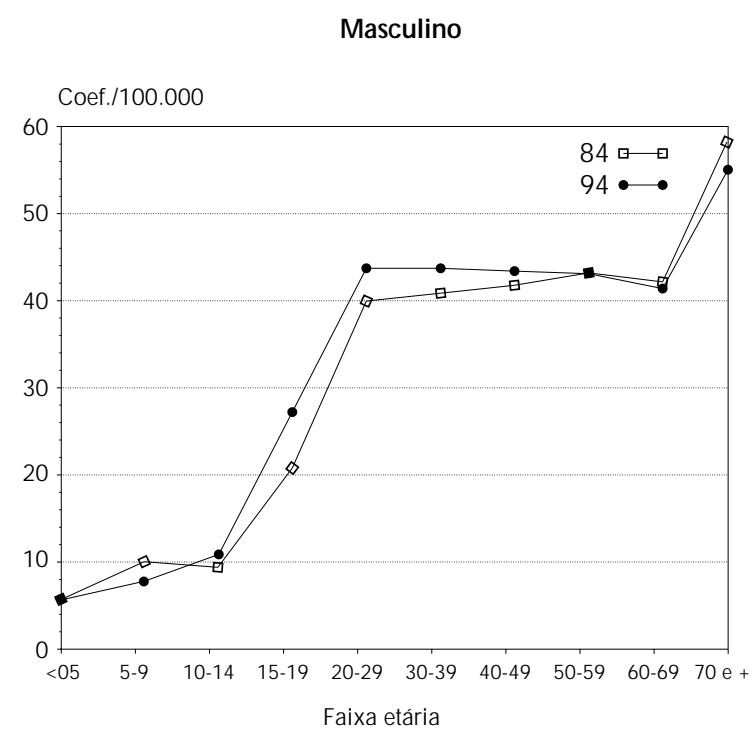

Figura 6 - Coeficientes de mortalidade por homicídios segundo sexo e faixa etária. Brasil, 1984 e 1994. 
Tabela 4 - Coeficientes de mortalidade por causas externas segundo tipo (por 100.000 habitantes). Países selecionados, anos próximos a 1994.

\begin{tabular}{lccccc}
\hline \multirow{2}{*}{ País } & \multicolumn{3}{c}{ Tipo } & \multirow{2}{*}{ Total } \\
\cline { 2 - 4 } & Ac. Trâns. & Suic. & Homic. & Demais Ac. & \\
\hline França (1991) & 16,5 & 20,2 & 1,1 & 44,9 & 82,7 \\
Itália (1990) & 15,8 & 7,6 & 2,6 & 24,5 & 50,6 \\
México (1990) & 16,4 & 2,4 & 17,5 & 32,3 & 68,6 \\
USA. (1990) & 18,4 & 12,4 & 9,9 & 19,7 & 60,4 \\
Suécia (1990) & 8,7 & 17,2 & 1,3 & 31,2 & 58,4 \\
Argentina (1990) & 9,1 & 6,6 & 5,0 & 30,5 & 51,5 \\
Japão (1992) & 11,8 & 16,9 & 0,6 & 18,4 & 47,7 \\
Brasil (1994) & 18,9 & 3,9 & 21,2 & 17,5 & 69,5 \\
\hline
\end{tabular}

Fontes: 1. World Health Statistics Annual, 1993. (WHO, 1994)

2. Ministério da Saúde (dados brutos, para o Brasil)

de trânsito e as quedas), em relação ao componente intencional (onde, aliás, há predomínio acentuado dos suicídios sobre os homicídios) (Borbeau $\left.{ }^{4}, 1993\right)$.

A Tabela 4 ressalta, também, a necessidade do estudo dessas causas segundo tipo, pois alguns países, cujos coeficientes de mortalidade por causas externas estão em níveis tão altos ou maiores que os do Brasil, não apresentam taxas tão altas de homicídios, por exemplo. Em relação aos acidentes de trânsito, embora exibam taxas também altas, as do Brasil foram as maiores, visto que os países mais desenvolvidos conseguiram, em décadas anteriores, a diminuição dessas taxas. As maiores diferenças encontradas estão relacionadas com a mortalidade por homicídios e suicídios. Em relação aos primeiros, as taxas mais próximas são as exibidas pelo México $(17,5 / 100.000)$ e as mais distantes são vistas no Japão (0,6/100.000). Já com relação aos suicídios, os países mais avançados apresentam taxas bem maiores que as brasileiras, sendo que somente o México tem menor coeficiente que o do Brasil, 2,4/100.000 habitantes $\left(\mathrm{OMS}^{23}, 1994\right)$.

As causas externas de tipo ignorado, como já foi comentado, ocorrem em razão do preenchimento incompleto/inadequado das Declarações de Óbito, que deixam clara a existência de uma lesão/envenenamento (o que prova ser a morte decorrência de causa externa), mas fazendo permanecer como "ignorado" o tipo de causa externa que ocasionou essa lesão.

Para o País, como um todo, esse grupo de causas tem se mantido ao redor de $15 \%$. A presença desse tipo de falha nas estatísticas de mortalidade prejudica, enormemente, os programas de prevenção que devem ser realizados no setor, em razão, principalmente, do seu comportamento em algumas áreas onde a proporção é muito elevada (Tabela 5). No Rio de

Tabela 5 - Percentagem de óbitos por causas externas de tipo ignorado, em áreas selecionadas. Brasil, 1977 a 1994.

\begin{tabular}{lcccrrr}
\hline Ano & S. Luís & R. Janeiro & Porto Alegre & Porto Velho & Distr. Federal & Brasil \\
\hline 1977 & 26,6 & 13,8 & 12,4 & 13,0 & 15,7 & 15,7 \\
1978 & 27,2 & 18,5 & 37,4 & 14,4 & 29,0 & 18,6 \\
1979 & 24,6 & 16,4 & 34,6 & 3,2 & 27,4 & 20,7 \\
1980 & 27,9 & 26,9 & 35,4 & 16,3 & 40,4 & 19,3 \\
1981 & 1,1 & 22,5 & 32,0 & 7,3 & 22,7 & 17,0 \\
1982 & 9,8 & 44,0 & 36,0 & 6,6 & 5,7 & 17,4 \\
1983 & 30,9 & 39,6 & 40,7 & 17,6 & 12,1 & 14,4 \\
1984 & 29,7 & 40,3 & 40,3 & 12,0 & 5,5 & 11,4 \\
1985 & 22,5 & 44,7 & 39,9 & 11,1 & 2,9 & 14,4 \\
1986 & 15,4 & 47,9 & 43,0 & 13,3 & 2,1 & 16,4 \\
1987 & 10,1 & 31,2 & 44,5 & 14,8 & 1,6 & 15,0 \\
1988 & 4,7 & 53,6 & 14,3 & 14,1 & 0,4 & 15,5 \\
1989 & 1,3 & 49,7 & 21,3 & 1,3 & 0,7 & - \\
1990 & 1,3 & 12,9 & 16,2 & 1,6 & 0,1 & 8,9 \\
1991 & 1,0 & 44,8 & 9,5 & 1,6 & 13,4 \\
1992 & 1,2 & 67,0 & 12,1 & 4,0 & 0,2 & 10,4 \\
1993 & 4,9 & 54,2 & 27,5 & 7,7 & 0,4 & 12,9 \\
1994 & 4,0 & 54,8 & 10,6 & 11,8 & 0,5 & 13,3 \\
\hline
\end{tabular}


Janeiro, esses valores chegam a alcançar mais de 50\% das causas externas, e em Porto Alegre parece ter sido possível reduzir essa percentagem para cerca de $11 \%$, graças a esforços empreendidos pelos órgãos responsáveis pelas estatísticas de mortalidade. No Município de São Luís, MA, a diminuição foi também apreciável em função da metodologia utilizada pela Secretaria da Saúde que se baseia em informação adicional da imprensa para o esclarecimento de mortes catalogadas nessa rubrica (Soares $\left.{ }^{25}, 1988\right)$.

\subsection{D istribuição G eográfica: as Causas Externas nas Capitais Brasileiras}

O estudo da distribuição geográfica é fundamental para a compreensão dos fatores que levam à ocorrência das causas externas. A Tabela 6 mostra, para as capitais brasileiras, os valores das mortes por essas causas, do início ao fim do período analisado, 1977 a 1994.

Os dados de 1994 revelam que quase todas elas apresentam valores mais altos que a média brasileira, nesse ano, com exceção de algumas áreas do Nordeste. Os coeficientes mais elevados (acima de 100/100.000 habitantes) pertencem aos Municípios de Rio Branco, Boa Vista, Macapá, Aracaju, Vitória, Rio de Janeiro e Distrito Federal. Um segundo grupo, com níveis altos, é formado por Porto Velho, Recife, Manaus, Macéio, Salvador, São Paulo, Curitiba, Campo Grande e Goiânia, nos quais as taxas localizam-se entre 80 e 99/100.000 habitantes. O terceiro grupo, de nível intermediário, é constituído pelos Municípios de João Pessoa, Florianópolis, Porto Alegre e Cuiabá e Belo Horizonte, cujos valores encontram-se entre 60 e 79/100.000. O quarto grupo, composto pelas capitais cujos coeficientes encontram-se abaixo de 60/100.000 habitantes é formado por Belém, São Luís, e João Pessoa.

Analisando o crescimento no período, verificase que, com poucas exceções, os coeficientes apresentaram-se em ascensão:

- Região Norte - algumas das capitais dessa região exibem coeficientes dos mais altos do Brasil e o mesmo pode ser dito para o crescimento acumulado no período. Macapá foi aquela que apresentou o maior crescimento, $181 \%$, saindo de níveis moderados de mortalidade e chegando ao final do período com níveis mais elevados. Porto Velho apresentou taxas em níveis elevados em todo o período. Rio Branco mostrou aumento de $42 \%$, também chegando ao final do período com taxas bastante altas. Manaus apresentou oscilações em suas taxas durante todo o período, acumulando, entretanto, um aumento de $40 \%$. O crescimento de Boa Vista foi da ordem de $56 \%$. Belém tem as menores taxas da região, podendo, a sua mortalidade, ser classificada como intermediária em relação à média brasileira (houve decréscimo no período, foi da ordem de 27\%). Os dados para o Município de Palmas não se encontram disponíveis para o período.

- Região Nordeste - as capitais da região mostram dois padrões de taxas elevado/alto e baixo. Entre aquelas que apresentaram crescimento estão: $R e$ cife que finaliza o período com taxas elevadas e com aumento da ordem de $93 \%$ (um dos maiores do País); Natal, com cerca de 32\%, embora não se apresente com taxas altas ao final do período; Aracaju, com $113 \%$ e Salvador, com 43\%. Maceió, a despeito de apresentar taxas mais altas do que a do Brasil como um todo, teve um pequeno crescimento, $14 \%$. Já Teresina e João Pessoa revelaram diminuição nos seus coeficientes, a primeira em $16 \%$ e a última em $18 \%$. Fortaleza manteve suas taxas em níveis mais baixos e estáveis.

- Região Sudeste - localizam-se aí algumas das capitais que, no fim do período, têm os maiores coeficientes do País: Vitória, Rio de Janeiro e São Paulo. Belo Horizonte apresentou aumento de $9 \%$. Vitória teve aumento de $102 \%$, o Rio de Janeiro, de $45 \%$ e São Paulo, $59 \%$.

- Região Sul - à exceção de Porto Alegre, as outras duas capitais da região chegam a 1991, com taxas ligeiramente maiores que as do Brasil. Curitiba mostrou pequena variação em suas taxas (14\%). Porto Alegre teve aumento de 9\% e Florianópolis também cresceu, cerca de $61 \%$.

- Região Centro-Oeste - em relação aos níveis de seus coeficientes de mortalidade por causas externas, as capitais dessa região apresentam-se bastante homogêneas no final do período, quando todas apresentaram algum crescimento. Campo Grande teve aumento de $3 \%$ em suas taxas, Cuiabá apresentou-se com o crescimento da região $30 \%$. Goiânia teve o menor aumento, $12 \%$, e no Distrito $\mathrm{Fe}$ deral houve o maior crescimento (38\%).

Em 1994, a situação dos coeficientes de mortalidade por causas externas pode ser explicada pelo aumento de diferentes tipos de causas nas capitais, como por exemplo, acidentes de trânsito em Vitória, Goiânia, Macapá, Distrito Federal e Curitiba que já apresentaram dados elevados (Mello Jorge e Latorre ${ }^{20}$, 1994), e que, no período de 1989/94, tiveram sua situação agravada. Outra hipótese é o aumento expressivo na mortalidade por homicídios, como é o caso de Belém, Fortaleza, Recife, Salvador, Belo Horizonte, 
Rio de Janeiro, São Paulo, Curitiba e Porto Alegre, que já haviam sido estudados por Souza ${ }^{26}$ (1994), mostrando também valores crescentes, na maioria delas, até 1989 , o que se mantém para o período 91/92.

O grupo de óbitos por suicídio, por ser responsável por baixos coeficientes durante todo o período em, praticamente, todas as capitais, mostra que, ao menos do ponto de vista de freqüência, esse não é um problema dos mais preocupantes, sendo que, provavelmente, uma análise mais detalhada das mortes deste grupo, não contribuirá para esclarecer as causas desses aumentos. No entanto, pode haver subestimação em relação a esses dados, pois outras mortes por causas externas, tais como alguns acidentes (trânsito, quedas e outros), ou mesmo mortes devidas a outras causas, tais como cirrose hepática, podem estar encobrindo fenômenos de autodestruição, dos quais o suicídio em si é apenas um deles (Mello Jorge $^{16,17}, 1979$ e 1982; Cassorla e Smeke $\left.{ }^{6}, 1994\right)$. Questões culturais podem também contribuir para essa freqüência menor, de vez que a própria família pode tentar encobrir a morte por suicídio.

Não poucas vezes, os óbitos alocados nos diferentes tipos de causas externas não representam a totalidade das mortes por essas causas, problema já discutido e que ocorre em razão da qualidade da informação. O Município do Rio de Janeiro tem seus dados questionados em relação ao grande percentual de óbitos relacionados como "outras violências" (violências de tipo ignorado), fazendo suspeitar de subestimação das mortes devidas aos homicídios. Salvador é um outro exemplo, pois não apresentou nenhum óbito nessa categoria, mas teve $92,3 \%$ do total de mortes por causas externas, provavelmente por má qualidade da informação/codificação, classificadas no grupo "Demais Acidentes".

Em razão destas considerações, será analisada a evolução da mortalidade por acidentes de trânsito e homicídios para as capitais brasileiras, em três anos determinados. A Figura 7 apresenta os coeficientes de mortalidade por acidentes de trânsito para os anos de 1977, 1984 e 1994. Observa-se, para o ano de 1994, que apenas cinco capitais, entre as 26 cujos dados foram estudados, têm coeficientes menores que a média brasileira. Como, geralmente, as capitais são as maiores cidades de seus Estados, sugere tratar-se de problema que atinge, com mais intensidade as áreas urbanas de maiores aglomerados populacionais. Entretanto, esta premissa não parece ser válida quando se comparam as capitais entre si, já que os maiores valores pertencem a Florianópolis, Curitiba, Vitória, Campo Grande, Distrito Federal e Goiânia, e os menores valores pertencem a Salvador e Rio de
Janeiro. O que se pode perceber também é que, visivelmente, as taxas de mortalidade por acidentes de trânsito, nas capitais, estão crescendo (Figura 7). Além disso, verifica-se que, em algumas áreas, o problema tem se apresentado como grave desde 1977: Curitiba, por exemplo, esteve presente nos três momentos, com coeficientes altos, ocupando, respectivamente, primeiro e segundo postos entre todas as capitais; Goiânia, que se apresentava em sexto lugar em 1977, passa ao quarto em 1984 e atinge o quinto posto em 1991; o Distrito Federal foi a décima área no "ranking" apresentado para o início do período, não aparecendo entre os dez primeiros postos em 1984 e despontando em quinto lugar em 1994. Já Florianópolis, apontada como tendo taxas muito elevadas (Mello Jorge e Latorre ${ }^{20}$, 1994) está em primeiro lugar, no fim do período analisado.

Em relação ao diferencial nos coeficientes de mortalidade por acidentes de trânsito, observados no período estudado, verifica-se que:

- Região Norte: a maior de suas capitais chega em 1994 apresentando valores elevados, mais altos do que a média brasileira, e revelando crescimento no período: Macapá (variação de mais de 120\%), Rio Branco (variação de mais 45\%), Porto Velho com coeficientes estáveis e Boa Vista (crescimento de 47\%). Manaus e Belém diminuíram seus coeficientes no período: menos $12 \%$ e menos $53 \%$, respectivamente.

- As capitais localizadas na região Nordeste, à exceção de Recife, Natal e Aracaju, cujos crescimentos foram positivos, todas apresentaram alguma diminuição em suas taxas no período. Aracaju e Recife tiveram aumentos expressivos, respectivamente, $159 \%$ e $50 \%$.

- No Sudeste, Belo Horizonte exibe tendência estável, sendo que Vitória cresceu 77\% e o Rio de Janeiro apresentou diminuição de $76 \%$, embora este fato deva ser analisado com a ressalva da possibilidade de estar relacionado com a má qualidade da informação no Município, já discutido; pode-se concluir, portanto, que essa diminuição é artificial. São Paulo, também, mostrou um decréscimo em suas taxas da ordem de $12 \%$.

- No Centro-Oeste, quase todas as capitais apresentaram crescimento no período, sendo que Campo Grande se destaca, com 229\%. Cuiabá apresenta um dos menores coeficientes do País.

- No Sul, Curitiba aumentou em 10\%, Florianópolis em $96 \%$ e Porto Alegre permaneceu estável. Tanto Florianópolis quanto Curitiba apresentam alguns dos maiores coeficientes entre as capitais brasileiras já em 1984, mantendo essas posições em 1994. 
A Figura 8 apresenta os coeficientes de mortalidade por homicídios, para as capitais brasileiras em três momentos distintos, já referidos para os acidentes de trânsito. Entre as 26 capitais estudadas, dez delas apresentam coeficientes menores que as médias
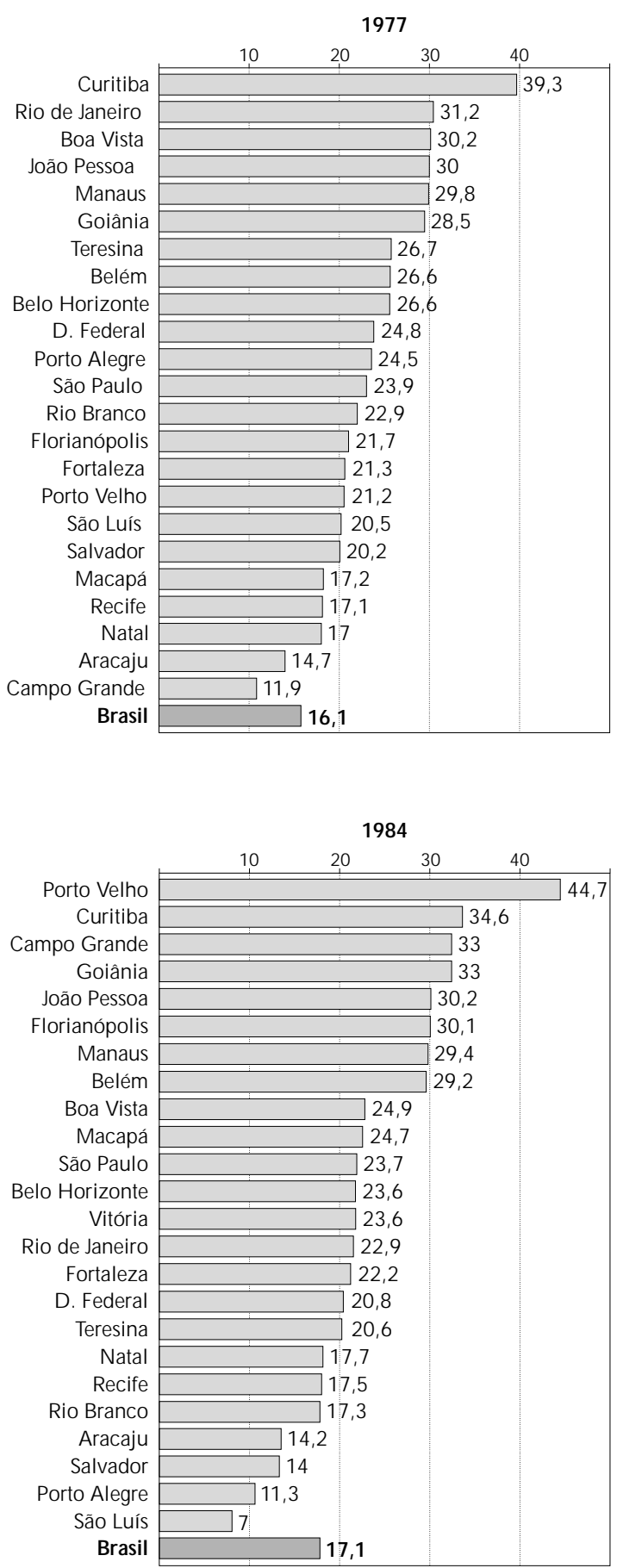

do Brasil. Para o ano de 1994, Vitória, Recife, Macapá, São Paulo e Aracaju ocupam os cinco primeiros lugares. Inversamente, Florianópolis, Cuiabá, Belo Horizonte e Natal são as capitais que apresentaram os menores coeficientes.

Em relação à evolução dos coeficientes de mortalidade por homicídios no período, os percentuais de aumento são bem mais altos que os apresentados para as causas externas como um todo e para os acidentes de trânsito, em especial, mostrando a importância que os homicídios vêm assumindo entre as causas de morte na população brasileira.

- As capitais da Região Norte do País apresentam, além de valores elevados, crescimento acentuado no período: Manaus (176\%), Rio Branco (150\%), Macapá (898\%) e Boa Vista (409\%) e Belém (66\%).

- Na Região Nordeste destacou-se o crescimento ocorrido em Aracaju (394\%), em Recife (335\%) e em São Luís (160). Teresina, Fortaleza e João Pessoa mantiveram-se em níveis estáveis. $\mathrm{O}$ aumento revelado por Natal, da ordem de $1.145 \%$ e em Salvador $(727 \%)$ deve ser analisado com reservas, visto que em 1977, estas capitais apresentavam valores muito baixos, difíceis de serem aceitos como verdadeiros.

- Na Região Sudeste, Vitória teve aumento de $454 \%$ em seus coeficientes e, atualmente, é a capital com maior taxa por homicídio. São Paulo(337,4\%) e

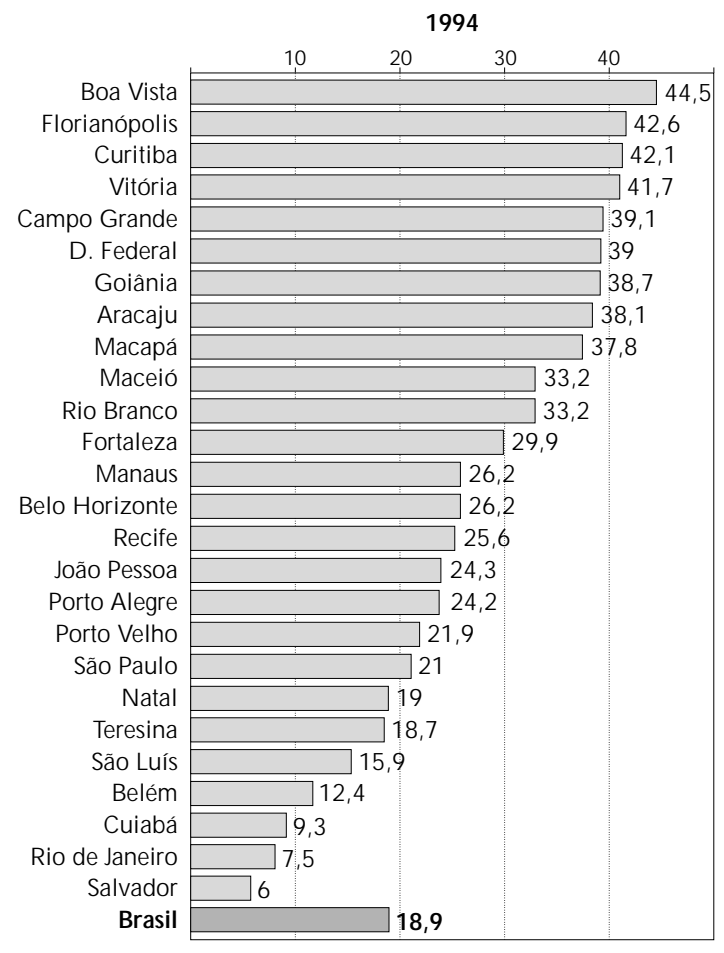

Figura 7 - M ortalidade por acidentes de trânsito (coeficientes/100.000 habitantes) segundo as capitais brasileiras. Brasil, 1977 , 1984 e 1994. 
Rio de Janeiro (63\%) também mostraram acréscimo em suas taxas. Em Belo Horizonte o decréscimo foi da ordem de $10 \%$.

- Todas as capitais da Região Sul apresentaram aumento em seus coeficientes, embora o percentual de aumento tenha variado entre esses Municípios: enquanto Curitiba apresentou acréscimo de 73\%, Florianópolis teve aumento de 183,3\% (mas como iniciou a série com valores muito baixos, chega a 1994 entre as capitais brasileiras que apresentam as menores taxas). Em Porto Alegre o aumento foi de $90 \%$. Todas as capitais da região Sul apresentam coeficientes menores do que a média brasileira.

- Na Região Centro-Oeste, todas as capitais tiveram aumentos em seus coeficientes. O maior ficou por conta de Cuiabá (392\%), embora em 1994 ainda apresente valores baixos. O Distrito Federal teve aumento de $148 \%$ e Goiânia de $37 \%$. Os dados do ano de 1977, para Campo Grande, não estavam disponíveis.

A situação do Rio de Janeiro merece considerações à parte, visto que pelos dados apresentados na Figura 8, esse município não exibe taxas das mais altas do País e o seu crescimento é de $63 \%$, contrariando um pouco o senso comum, que coloca essa cidade como uma das mais violentas do País. Souza ${ }^{26}$

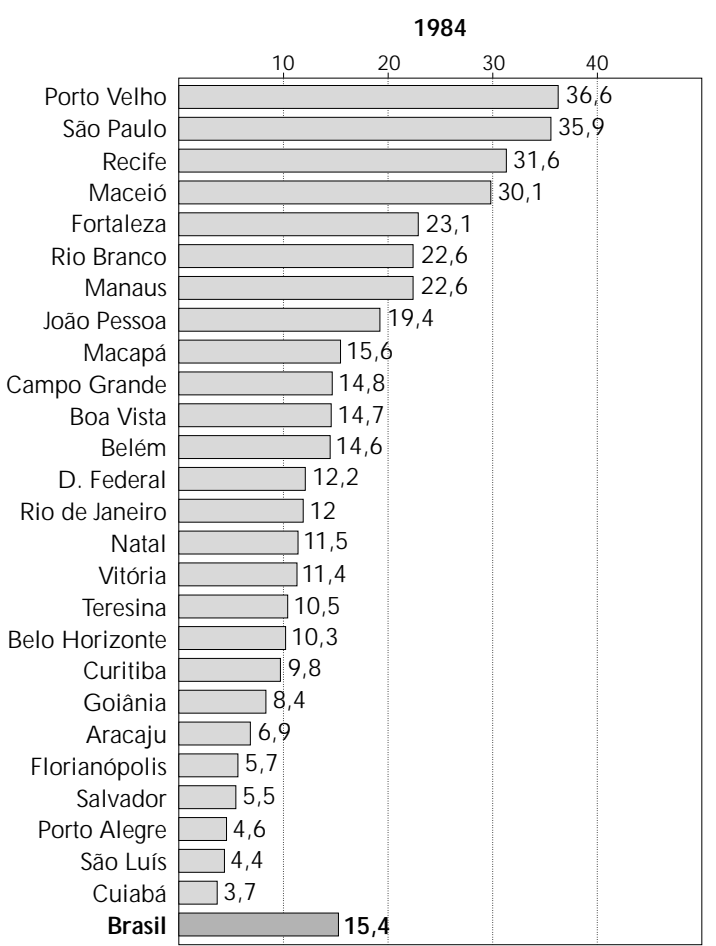

(1994) já apontou que muitos dos óbitos classificados como lesões em que se ignora se foram acidentais ou intencionais são, na verdade, homicídios. Essa autora, inclusive, soma os óbitos por arma de fogo desse grupo ignorado aos homicídios e, para o ano
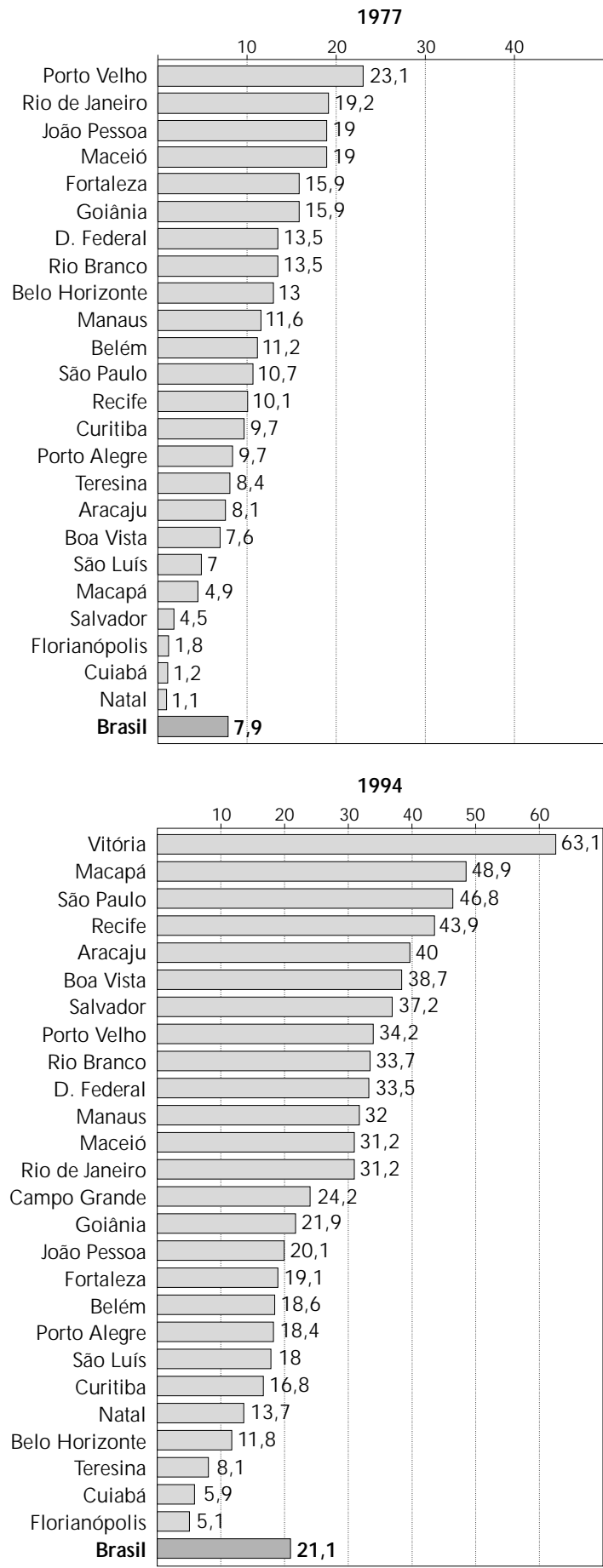

Figura 8 - M ortalidade por homicídios (coeficientes/100.000 habitantes) segundo as capitais brasileiras. Brasil, 1977, 1984 e 1994. 
de 1989, observou que essas taxas triplicaram fazendo com que essa capital assumisse o primeiro posto entre todas as capitais do Brasil.

Em relação ao peso dessas causas entre o total das causas externas, a análise das Figuras 7 e 8, em conjunto, mostra que na região Norte, apenas Rio Branco apresenta o componente de acidentes de trânsito semelhante ao de homicídos; já as demais capitais têm o componente principal de suas causas externas composto pelos homicídios. No Nordeste, em Teresina, Natal e João Pessoa são os acidentes de trânsito que predominam; em Fortaleza e Maceió há equilíbrio nestes coeficientes, e em Recife, Salvador e São Luís os homicídios ocupam o primeiro lugar. Na região Sudeste predominam os homicídios em todas as capitais, à exceção de Belo Horizonte. No Centro Oeste e Sul do País, há predominância dos acidentes de trânsito. Em resumo, é, principalmente, nas regiões Norte e Sudeste do País que os homicídios já se apresentam à frente dos acidentes de trânsito nas mortes por causas externas.

Com referência aos homicídios, é importante o estudo do meio pelo qual eles são perpetrados, pois contribuem para mostrar os caminhos para onde as medidas de prevenção devem ser encaminhadas. A precariedade deste dado já foi assinalada por Sou$\mathrm{za}^{26}$ (1994) que estimou, para o ano de 1989, que a contribuição das armas de fogo para o total das causas externas no Brasil foi de $26 \%$. Outros estudos apontam valores mais altos: Gawryszewski ${ }^{8}$ (1995) mostrou que, para o ano de 1991, 91\% dos homicídios em menores de 20 anos foram cometidos por este meio. Nos Estados Unidos, as mortes devidas às armas de fogo têm grande importância; o editorial do JAMA $^{27}$ (1992) revela que, enquanto a população dos Estados Unidos cresceu cerca de 26\%, entre 1960 e 1980, as taxas de homicídios devidas às armas de fogo cresceu $160 \%$. Além disso, há preocupação em relação ao uso de armas de fogo pelos jovens. $\mathrm{O}$ mesmo editorial cita que um terço dos jovens que freqüentam "high school" no Estado de Illinois costuma levar armas para a escola, com o intuito de se defender.

A partir do crescimento da mortalidade por causas externas verificado na maior parte das capitais brasileiras, no período estudado, considerou-se importante mostrar o peso dos diferentes tipos de causas externas na evolução desses coeficientes globais, para o que foi construída a Tabela 6. Chama atenção o aumento expressivo verificado nos coeficientes de mortalidade por homicídios, que ocorreu na maior parte das capitais. Os acidentes de trânsito variam conforme o local: alguns municípios ex- perimentam decréscimo nessas taxas, enquanto outros ainda apresentam crescimento acentuado. $\mathrm{O}$ grupo dos "demais acidentes", de um modo geral, teve discretas variações, para mais ou para menos, não parecendo pesar muito nas taxas globais dessas capitais. Em relação à mortalidade por suicídios, é preciso analisar com ressalvas o aumento identificado em seus coeficientes, principalmente nos municípios menos populosos, pois embora pareçam expressivos, são valores baixos que não têm peso nos valores globais, pois provêm de números absolutos pequenos.

\section{CONSIDERAÇÕ ES FIN AIS}

No presente trabalho foi mostrado o crescimento da importância das causas externas para a população brasileira, através dos coeficientes de mortalidade por essas causas, no período de 1977 a 1994. Chama atenção, principalmente, o crescimento dos homicídios (da ordem de 160\%) para o Brasil como um todo; foi o maior percentual de crescimento entre os tipos de causas externas, apontando um problema grave e crescente, a ser enfrentado no País (Tabela 6).

As grandes diferenças e semelhanças encontradas nos coeficientes de mortalidade das várias capitais do País levam a alguns questionamentos importantes: o que pode aproximar, por exemplo, Porto Velho e Rio Branco do Rio de Janeiro, Vitória e São Paulo? Em princípio, as três últimas capitais citadas, acrescentando-se Recife, remetem à discussão da questão do cenário urbano como facilitador/favorecedor da violência, pela concentração populacional, concentração de riqueza, pela impessoalidade nas relações sociais, entre outros, que, sem dúvida, devem contribuir para o aumento da violência. Por outro lado, isto não explica o fato de Belo Horizonte ter atravessado a década sem ter aumentado suas taxas. E mesmo, Porto Velho e Rio Branco que, embora tenham experimentado processo de ocupação e urbanização recentes (Zaluar e col. $\left.{ }^{30}, 1994\right)$, não são cidades que possam se comparar, em contingente populacional e estrutura urbana, ao Rio de Janeiro, São Paulo e Recife.

É preciso, entretanto, separar as capitais cujos maiores coeficientes são devidos aos acidentes de trânsito, que têm determinantes diversos daqueles relativos aos homicídios. Para elas seria interessante ter uma idéia do processo de urbanização e da frota de veículos na última década, o que certamente, num primeiro momento, favoreceria o aumento da mortalidade por acidentes de trânsito. Na verdade, essas 
Tabela 6: Evolução dos coeficientes de mortalidade segundo tipo de causa externa. Capitais brasileiras, 1977 e 1994.

\begin{tabular}{|c|c|c|c|c|c|}
\hline Capitais/Região & Ac. Trâns. & Demais ac. & Suicídios & Homic. & Total \\
\hline \multicolumn{6}{|l|}{ Norte } \\
\hline Porto Velho & $\rightarrow$ & $\uparrow$ & $\uparrow$ & $\uparrow \uparrow \uparrow$ & $\rightarrow$ \\
\hline Rio Branco & $\uparrow \uparrow \uparrow$ & $\rightarrow$ & $\uparrow \uparrow \uparrow$ & $\uparrow \uparrow \uparrow$ & $\uparrow$ \\
\hline Manaus & $\uparrow \uparrow \uparrow$ & $\rightarrow$ & $\uparrow \uparrow$ & $\uparrow \uparrow \uparrow$ & $\uparrow$ \\
\hline Boa Vista & $\uparrow \uparrow \uparrow$ & $\uparrow$ & $\uparrow \uparrow \uparrow$ & $\uparrow \uparrow \uparrow$ & $\uparrow \uparrow$ \\
\hline Belém & $\uparrow \uparrow$ & $\rightarrow$ & $\uparrow \uparrow \uparrow$ & $\uparrow \uparrow$ & $\downarrow \downarrow$ \\
\hline Macapá & $\uparrow \uparrow \uparrow$ & $\uparrow$ & 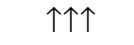 & 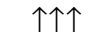 & $\uparrow \uparrow \uparrow$ \\
\hline \multicolumn{6}{|l|}{ Nordeste } \\
\hline São Luís & $\downarrow$ & $\uparrow$ & $\uparrow$ & $\uparrow \uparrow \uparrow$ & $\rightarrow$ \\
\hline Teresina & $\downarrow$ & $\downarrow$ & $\uparrow$ & $\rightarrow$ & $\downarrow$ \\
\hline Fortaleza & $\rightarrow$ & $\downarrow$ & $\uparrow$ & $\uparrow$ & $\rightarrow$ \\
\hline $\mathrm{N}$ atal & $\uparrow \uparrow$ & $\downarrow$ & $\uparrow \uparrow \uparrow$ & $\uparrow$ & $\uparrow$ \\
\hline João Pessoa & $\downarrow$ & $\ldots$ & $\downarrow$ & $\rightarrow$ & $\rightarrow$ \\
\hline Recife & $\uparrow \uparrow$ & $\uparrow \uparrow$ & $\uparrow \uparrow$ & $\uparrow \uparrow$ & $\uparrow \uparrow$ \\
\hline Maceió & $\ldots$ & $\rightarrow$ & $\uparrow \uparrow \uparrow$ & $\uparrow \uparrow$ & $\uparrow$ \\
\hline Aracaju & $\uparrow \uparrow$ & $\downarrow$ & $\uparrow \uparrow \uparrow$ & $\uparrow \uparrow \uparrow$ & $\uparrow \uparrow \uparrow \uparrow$ \\
\hline Salvador & $\downarrow \downarrow$ & $\ldots$ & $\ldots$ & $\uparrow \uparrow \uparrow$ & $\uparrow$ \\
\hline \multicolumn{6}{|l|}{ Sudeste } \\
\hline Belo Horizonte & $\rightarrow$ & $\downarrow$ & $\downarrow$ & $\rightarrow$ & $\rightarrow$ \\
\hline Vitória & $\uparrow$ & $\uparrow$ & $\ldots$ & $\uparrow \uparrow \uparrow$ & $\uparrow \uparrow \uparrow$ \\
\hline Rio de Janeiro & $\downarrow \downarrow$ & $\downarrow$ & $\ldots$ & $\uparrow \uparrow$ & $\uparrow$ \\
\hline São Paulo & $\downarrow$ & $\uparrow$ & $\rightarrow$ & $\uparrow \uparrow \uparrow$ & $\uparrow \uparrow$ \\
\hline \multicolumn{6}{|l|}{ Sul } \\
\hline Curitiba & $\rightarrow$ & $\rightarrow$ & $\rightarrow$ & $\uparrow \uparrow$ & $\rightarrow$ \\
\hline Florianópolis & $\uparrow \uparrow$ & $\downarrow$ & $\uparrow$ & $\uparrow \uparrow \uparrow \uparrow$ & $\uparrow \uparrow$ \\
\hline Porto Alegre & $\rightarrow$ & $\uparrow \uparrow$ & $\downarrow$ & $\uparrow \uparrow$ & $\rightarrow$ \\
\hline \multicolumn{6}{|l|}{ Reg. C. O este } \\
\hline Campo Grande & $\uparrow \uparrow \uparrow$ & $\ldots$ & $\downarrow$ & $\ldots$ & $\uparrow$ \\
\hline Cuiabá & $\ldots$ & $\ldots$ & $\ldots$ & $\uparrow \uparrow \uparrow$ & $\uparrow$ \\
\hline Goiânia & $\uparrow \uparrow$ & $\downarrow$ & $\downarrow$ & $\uparrow$ & $\uparrow$ \\
\hline Distr. Federal & $\uparrow \uparrow$ & $\downarrow$ & $\uparrow \uparrow \uparrow$ & $\uparrow \uparrow \uparrow$ & $\uparrow$ \\
\hline \multicolumn{6}{|l|}{ genda: } \\
\hline $\begin{array}{l}\text { - aumento ou dimin } \\
\text { - aumento de } 10 \mathrm{a} \\
\text { - aumento de } 50 \mathrm{a} \\
\uparrow \text { - aumento de } 100 \%\end{array}$ & & $\begin{array}{cc}\downarrow & \text { - diminui } \\
\downarrow \downarrow & - \text { diminui } \\
\downarrow \downarrow \downarrow & \text { - diminui }\end{array}$ & $\begin{array}{l}49 \% \\
99 \% \\
\% \text { e mais }\end{array}$ & & \\
\hline
\end{tabular}

capitais, apontadas como as de maiores taxas de mortalidade por causas externas no Brasil, têm nos homicídios o seu componente principal, já chamado por Souza $^{26}$ (1994) de o "grande vilão da Saúde Pública na década de 80 ". Portanto, resta discutir, mesmo que de forma limitada, alguns aspectos deste fenômeno. Zaluar e col. ${ }^{30}$ (1994) acentuam o papel do crime organizado, existência de tráfico de drogas e armas como os fatores predominantes para o estabelecimento da criminalidade urbana, chegando a concluir que o binômio violência e pobreza, tão comumente associados, devem ser separados, visto que alguns dos locais mais pobres do País não apresentam taxas altas para os homicídios. Esse fato pode ser observado para a maior parte das capitais do Nordeste e o contrário pode ser dito em relação a uma das capitais mais ricas do País, São Paulo, embora também apontem a falta de instituições adequadas para o combate da pobreza urbana como sendo mais um fator favorecedor do estabelecimento da criminalidade naqueles locais. Segundo esses citados autores, a presença desses fatores estimulariam a "competição individual desenfreada, com pouco ou nenhum limite institucional nas conquistas e na resolução dos conflitos interpessoais". Na região Norte, contribuiria, além do que já foi citado, a existência de frentes de garimpo e de conflitos de terra, para as altas taxas lá verificadas. 


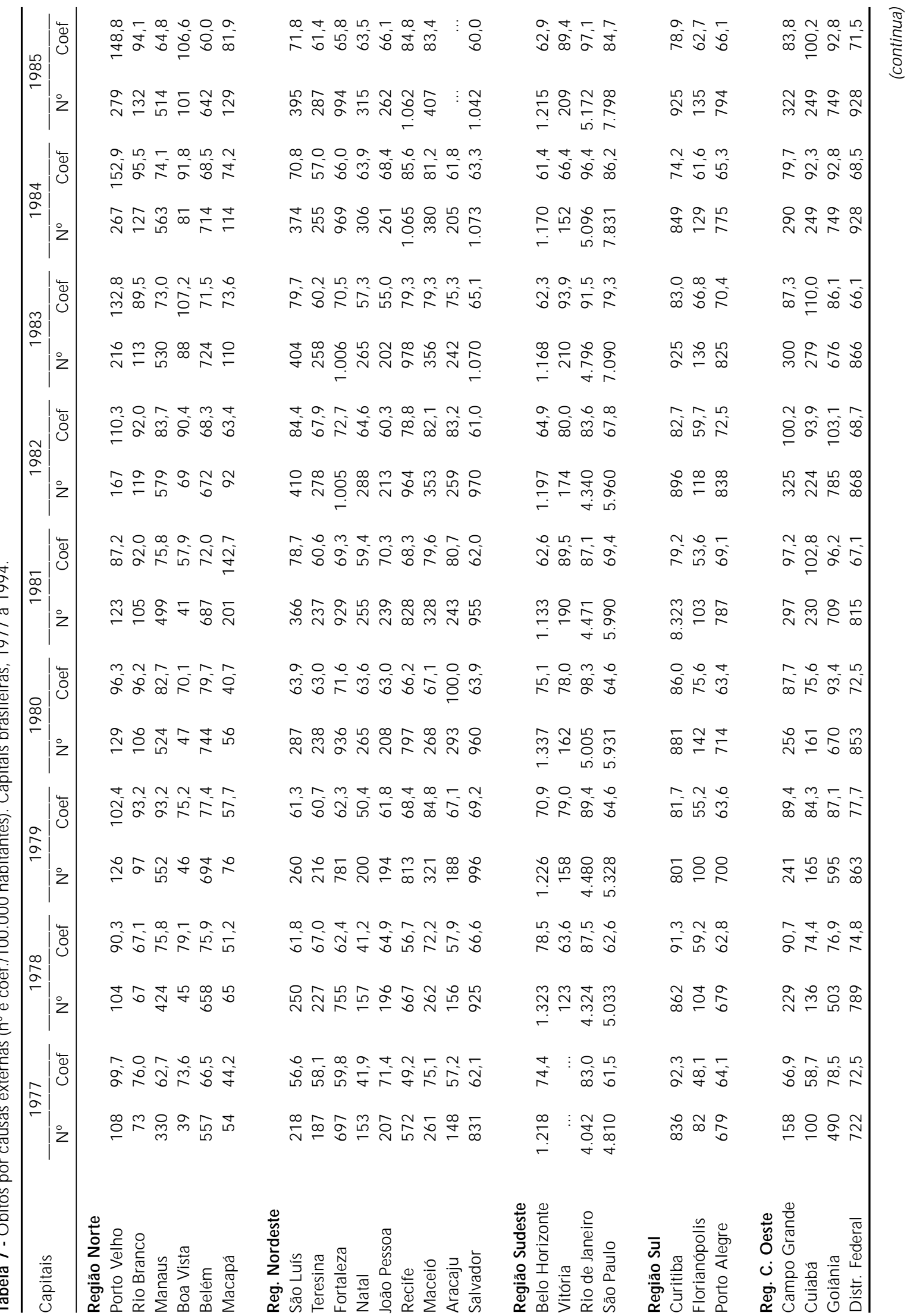




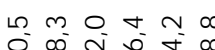

过售

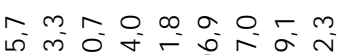

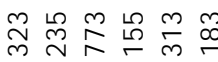

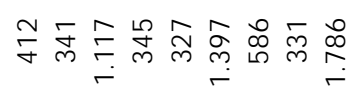

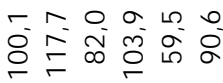

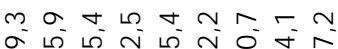

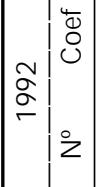

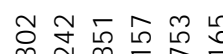

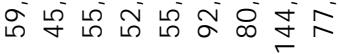

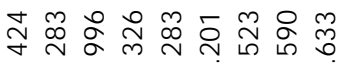

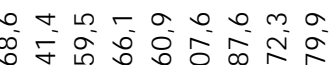

$\begin{array}{llllll}0 & 0 & 0 & 0 & 0 \\ 0 & 0 \\ 0 & 0 & 0 & 0 \\ 7 & 0 & 0 & 0 & 0 \\ 7 & 0 & 7 & 0\end{array}$

ने|

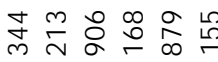

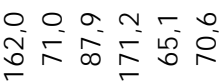

ิㅟำ

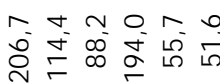

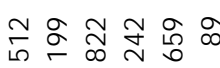

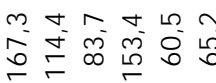

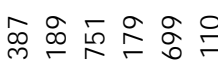

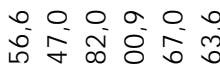

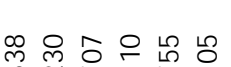

m

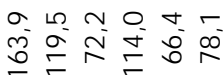

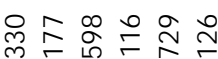

$$
\text { ร }
$$

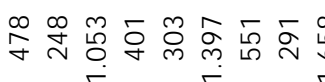

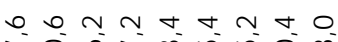

ธิ์

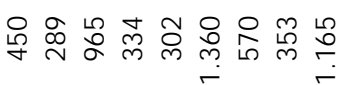

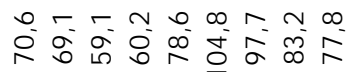

भु̆

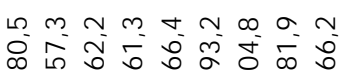

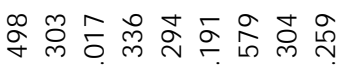

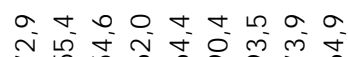

ำนี้ ถิ่

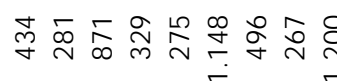

ก 0 ก

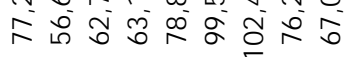

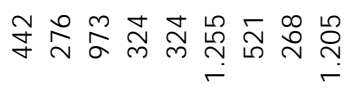

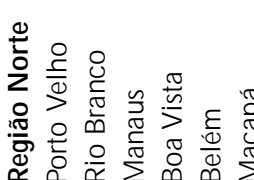

$\frac{8}{8}$

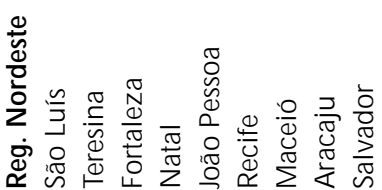

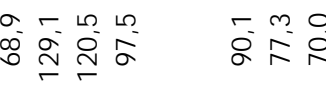

ฟิ

$\rightarrow \quad 6 \sigma$

ז.

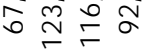

$\stackrel{m}{m} \rightarrow \frac{m}{i}$

苍

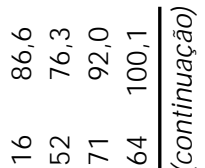

$m \sim m m$

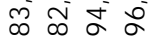

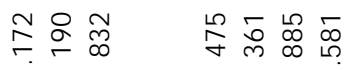

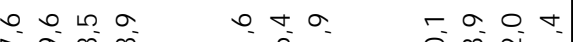

के

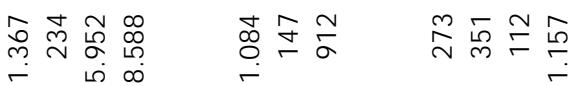

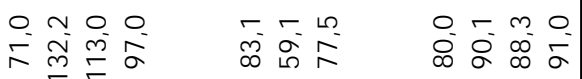

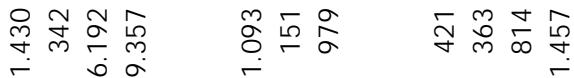

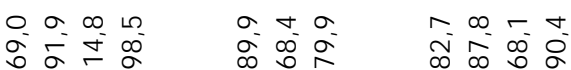

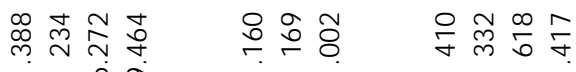

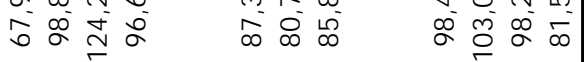

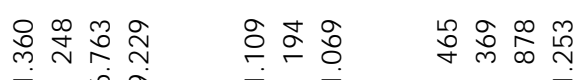

$\begin{array}{lllll}- & 0 & - & -1\end{array}$

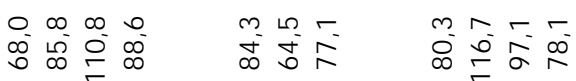

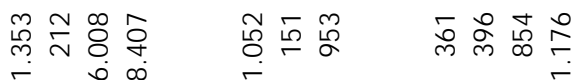

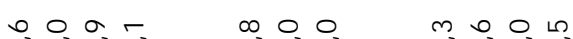

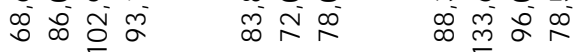

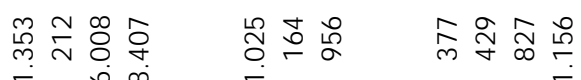

$\infty \forall m m \quad \sigma m+\quad \sigma+c u$

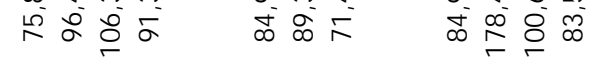

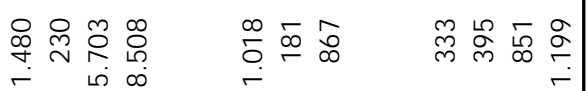

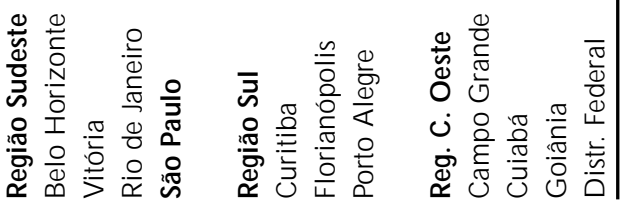


A má qualidade da informação, que ainda persiste em algumas dessas capitais, como já foi comentado, prejudica, enormemente, o conhecimento do problema, base para qualquer medida preventiva.

A partir dessas altas taxas de mortalidade por causas externas (Tabela 7) encontradas no presente estudo e em outros, anteriormente realizados e que fazem parte da bibliografia que foi citada, a prevenção da morbi-mortalidade pelos acidentes e violências na população brasileira se faz hoje uma questão de indiscutível urgência. É claro que o conhecimento epidemiológico do problema não basta sozinho, visto estar-se diante de um fenômeno complexo, com vários determinantes e com soluções difíceis e tra-

\section{REFERÊN CIAS BIBLIO G RÁFICAS}

1. ALLGULANDER, C. \& LAVORI, P.W. Causes of death among 936 elderly patients with "pure" anxiety neurosis in Stckholm County, Sweden, and in patients with depressive neurosis or both diagnoses. Compr. Psychiatry, 34 : 299-302, 1993.

2. BECKER, R.A. Análise da mortalidade: delineamentos básicos. Fundação Nacional de Saúde, Brasília, 1991.

3. BEECK, E.F. et al. Determinants of traffic accident mortality in the Netherlands: a geographical analysis. Int. J. Epidemiol., 20 : 698-706, 1991.

4. BOURBEAU, R. Analisé comparative de la mortalité violente dans les pays développes et dans quelques pays en développement durant la période 1985-1989. World Health Stat. Q., 46: 4-32, 1993.

5. CASEDEBAIG, F. \& PHILIPPE, A. Mortality due to suicide, accidents and undetermined causes in hospitalized mental patientes 1968-1982. Rev. Epidemiol. Sante Publique, 40: 126-35, 1992.

6. CASSORLA, R.M.S. \& SMEKE, E.L.M. Autodestruição humana. Cad. Saúde Pública, 10 (supl. 1): 61-73, 1994.

7. CENTERS FOR DISEASE CONTROL. Firearm-related deaths - Louisiania and Texas, 1970-1990. JAMA, 267 (22): 3008, 1992.

8. GAWRYSZEWSKI, V.P. A mortalidade por causas externas no Município de São Paulo, 1991. São Paulo, 1995. [Dissertação de Mestrado - Faculdade de Saúde Pública da USP].

9. FUNDAÇÃO IBGE. Censo Demográfico de 1970. Rio de Janeiro, 1973.

10. FUNDAÇÃO IBGE . Censo Demográfico de 1980. Rio de Janeiro, 1982.

11. FUNDAÇÃO IBGE. Censo Demográfico de 1991. Rio de Janeiro, 1993. balhosas, que exigem investimento de recursos e mudanças mais gerais na sociedade. É evidente, entretanto, que cabe ao setor saúde e, mais especificamente à Saúde Pública e à Epidemiologia, apontar e identificar quais os grupos e fatores de risco, porque é isto, afinal, que pode auxiliar a estabelecer algumas dessas estratégias de prevenção.

\section{AGRADECIMENTOS}

Aos bolsistas de Iniciação Científica do CNPq, Cláudia Simone Kuada, Celina Mayumi Takigahira e Renata de Carvalho Berni, que trabalharam com os bancos de dados de mortalidade e colaboraram nas estimativas de população.

12. FUNDAÇÃO SEADE. Anuário estatístico do Estado de São Paulo. São Paulo, 1992.

13. JEANNERET, O. \& SAND, E.A. Intentional violence among adolescents and young adults: an epidemiological perspective. World.Health.Stat.Q., 46 209-10, 1993.

14. LAURENTI, R. \& MELLO JORGE, M.H.P. $O$ atestado de óbito. 2a. ed. São Paulo. Centro Brasileiro de Classificação de Doenças, 1987.

15. MACHADO, J.M.H. \& MINAYO GOMEZ, C. Acidentes de trabalho: uma expressão da violência social. Cad. Saúde Pública, 10 (supl. 1): 74-87, 1994.

16. MELLO JORGE, M.H.P. Mortalidade por causas violentas no Município de São Paulo. São Paulo, 1979. [Tese de Doutoramento - Faculdade de Saúde Pública da USP].

17. MELLO JORGE, M.H.P. Mortalidade por causas violentas no Município de São Paulo, Brasil. IV - A situação em 1980. Rev. Saúde Pública, 16 :19-41, 1982.

18. MELLO JORGE, M. H. P. Investigação sobre a mortalidade por acidentes e violências na infância, São Paulo, 1985. São Paulo, 1988. [Tese de Livre Docência - Faculdade de Saúde Pública da USP].

19. MELLO JORGE, M.H.P. O Sistema de Informação de Mortalidade: diagnóstico do período 1977 a 1990. São Paulo, 1993 [mimeografado].

20. MELLO JORGE, M.H.P. \& LATORRE, M.R.D.O Acidentes de trânsito no Brasil: dados e tendências. $\mathrm{Cad}$. Saúde Pública, 10 (supl. 1): 19-44, 1994.

21. MINISTÉRIO DA SAÚDE. Estatísticas de mortalidade; Brasil. 1977 a 1989. Brasília,1993.

22. ORGANIZAÇÃO MUNDIAL DA SAÚDE. Manual de classificação estatística internacional de doenças lesões e causas de óbito; $9^{\mathrm{a}}$ rev., 1975. São Paulo, Centro da OMS para Classificação das Doenças em Português, 1979. 
23. ORGANIZAÇÃO MUNDIAL DE SAÚDE - World health statistics annual 1993. Geneva, 1994.

24. ORGANIZAÇÃO PANAMERICANA DE LA SALUD. Las condiciones de salud en las Américas. Washington, DC, 1994, vol. 1.

25. SOARES, W. Contribuição da imprensa para correção de dados de mortalidade por causas externas. São Luís, 1988 [mimeografado].

26. SOUZA, E.R. Homicídios no Brasil: o grande vilão da saúde pública na década de 80. Cad. Saúde Pública, 10 (supl. 1):45-60, 1994
27. VIOLENCE in America: a public health emergency. JAMA, 267 (22):3075, 1992.

28. YUNES, J. Mortalidad por causas violentas en la región de las Américas. Bol. Ofic. Sanit. Panam., 114: 303-15, 1993.

29. YUNES, J. \& RAJS, D. Tendencia de la mortalidad por causas violentas en la poblacion general y entre los adolescentes y jóvenes de la región de las Américas. $\mathrm{Cad}$. Saúde Pública, 10 (supl. 1): 88-125, 1994.

30. ZALUAR, A. et al. Violência: pobreza ou fraqueza institucional? Cad. Saúde Pública, 10 (supl. 1): 213-7, 1994. 